\title{
Chapter
}

\section{Liquid-phase synthesis of nanoparticles and nanostructured materials}

\author{
Ali Karatutlu ${ }^{* * * *, \dagger}$, Ahmed Barhoum $^{\ddagger, \S}$ and Andrei Sapelkin ${ }^{\dagger}$ \\ *UNAM-National Nanotechnology Research Center Bilkent University Ankara Turkey, Çankaya/Ankara, Turkey; \\ **The Institute of Materials Science and Nanotechnology Bilkent University Ankara Turkey, Çankaya/Ankara, Turkey; \\ ${ }^{\dagger}$ Queen Mary University of London, London, United Kingdom; ${ }^{\star}$ Vrije Universiteit Brussel (VUB), Brussels, Belgium;
} ${ }^{\S}$ Helwan University, Helwan, Cairo, Egypt

\section{INTRODUCTION}

Many breakthroughs over 30 years have emerged following the advent of nanomaterials (NMs) research in natural sciences and engineering. Reducing the size of materials down to nanoscale leads to produce NMs with profound changes in its physical properties relative to the macro scale form [1]. This results in applications of nanostructured materials including optoelectronics, magnetic storage memory devices, and biomedical applications. To manufacture such NMs, two main approaches are carried out as follows: (1) top-down approach usually employs physical methods, for example, mechanical grinding, and (2) bottom-up approach often utilizes solution-phase chemistry, that is, wet chemical synthesis.

Liquid-phase synthesis methods have several advantages over other gasphase and solid-phase synthesis methods [2,3]. For example, (1) liquidphase synthesis is the most common synthesis methods for preparing nanoparticles (NPs) and nanostructured materials together with the gas-state synthesis (Fig. 1.1) [4]; (2) size and shape control of NMs obtained could be achieved at low temperature within a short time from minutes to hours; (3) production of the NPs and nanostructures carried out with reasonably low-cost particularly compared to solid-phase synthesis methods; (4) experimental processes in the liquid-phase synthesis are rather simple with high mass yield; (5) conventional benchtop chemistry is applied with common reagents and equipment [5]; (6) surface functionalization can be achieved in situ with respect to the application field. This gives a complete control 


\section{CHAPTER 1 Liquid-phase synthesis of nanoparticles and nanostructured materials}

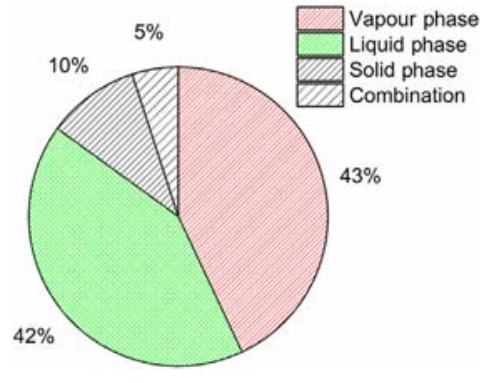

IFIGURE 1.1 Various methods for formation of NMs. The liquid-phase synthesis is reported as one of the most widespread synthesis technique together with the gas-state synthesis. (From Charitidis, C.A., Georgiou, P., Koklioti, M.A., Trompeta, A.-F., Markakis, V., 2014. Manufacturing nanomaterials: from research to industry. Manuf. Rev. 1, 11. under the CC BY 4.0 license). on changing their physical properties; (7) size and shape of NPs and nanostructures could be controlled quite well by the most liquid-phase synthesis methods (depending on the method used). Chemical purification and size separation techniques, such as chromatography and high-performance liquid chromatography (HPLC) are not required; (8) postsynthesis techniques are available for formation of clusters [6] and $2 \mathrm{~d}$ superlattices [7] from the as-prepared NPs and nanostructures.

The liquid-phase synthesis can be classified into: (1) top-down approaches, where bulk materials are etched in an aqueous solution for producing NPs or nanostructures, for example, the synthesis of porous silicon by electrochemical etching; and (2) bottom-up approaches, where atoms/molecules via self-assembly, in general, are gathered together to form NMs and mixed in a controlled fashion to form a colloidal solution (Fig. 1.2). NPs produced by liquid-phase synthesis methods can remain in liquid suspension for further use or may be collected by filtering or by spray drying to produce a dry powder.

Liquid-phase synthesis methods from a solution of chemical compounds include, but are not limited to, chemical stain etching, colloidal methods, coprecipitation, electrochemical deposition, direct precipitation, sol-gel processing, microemulsions method, reverse micelle synthesis, hydrothermal synthesis, template methods, polyol method, and laser ablation. In this

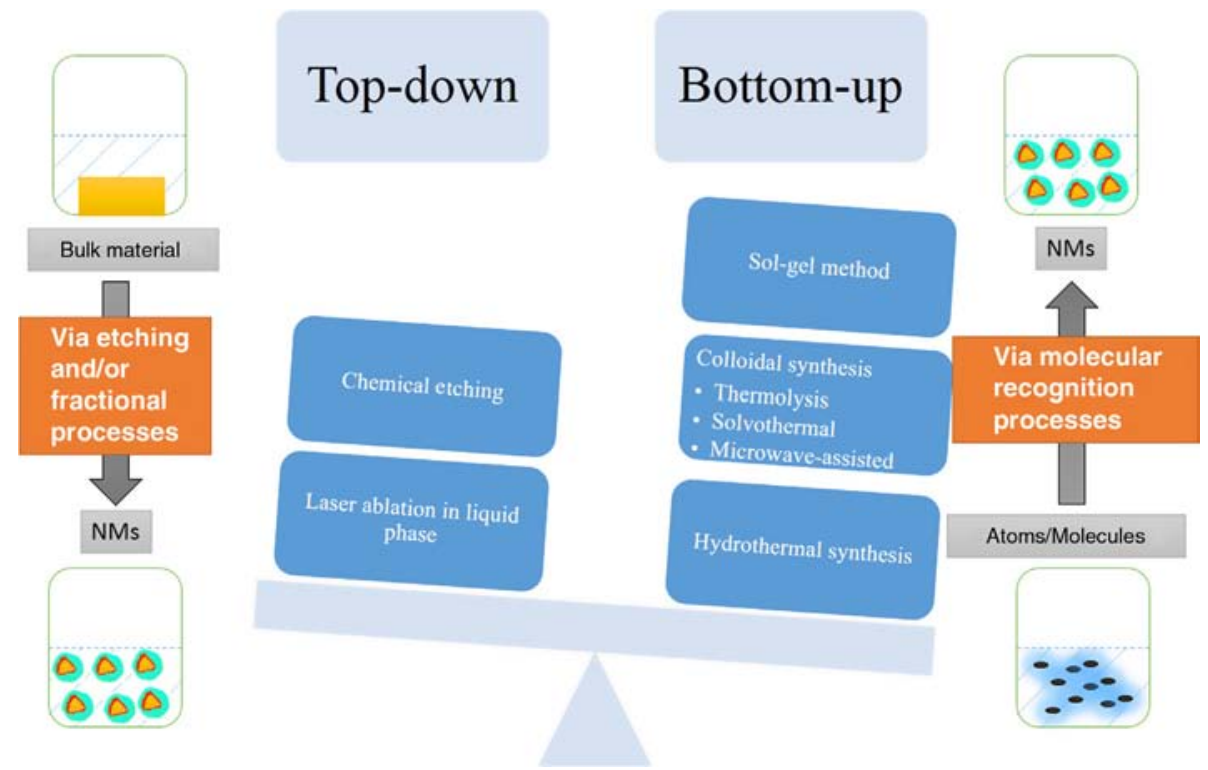

FIGURE 1.2 Schematic of the formation of NMs processes. Top-down versus bottom-up liquid-phase synthesis methods. 
chapter, we attempt to explain the methods of the most common liquid-phase synthesis particularly with a purpose for helping new researchers to choose the best suitable liquid-phase synthesis methods for their interest. Because it is impossible to include all the published works, the other brilliant studies and some of the liquid-phase synthesis methods left out involuntarily. An important subset of liquid-phase synthesis methods are sonochemistry methods and microwave-assisted methods, in which acoustic cavitation is used to control the process.

\section{CHEMICAL STAIN ETCHING}

Chemical stain etching is applied since the first studies on a bulk film of $\mathrm{Ge}$ and $\mathrm{Si}$, respectively, where an aqueous $\mathrm{HF} / \mathrm{HNO} 3$ solution was used as an etchant $[8,9]$. The solution continuously applies the etching process on the top surface of the oxidized bulk material from which NPs and nanostructures are formed without any applied bias. In other words, the bulk material, such as intrinsic silicon, has a surface is inert against HF in a dark or an unbiased environment. Focus on optoelectronic applications using this method began after room temperature luminescence was observed in electrochemically etched Si in 1991 [10]. Still, the light emission using this solution was not satisfactory [11]. Various ratios, such as an aqueous HF/ HNO3 solution with a respective volume ratio of 500:1, were studied for improving the light emission [12]. Other oxidizing agents, such as $\mathrm{H} 2 \mathrm{O} 2$, were also described [13].

Several other reaction conditions were reported. For example, the etching rate was also found to be dependent on the doping concentration [14]. Moreover, the metal-assisted oxidizing agents were also be found to be an efficient way for the formation of nanostructures $[15,16]$. Quenching and enhancement of the light emission have been observed to depend on the type of surface active agents (surfactants) [17,18]. Table 1.1 shows some examples of cationic and anionic surfactants.

The etching speed when forming nanostructures is also well known to be controlled by increasing the etchant acidity [13], such as $\mathrm{HCl}, \mathrm{H}_{2} \mathrm{SO}_{4}$, and $\mathrm{H}_{3} \mathrm{PO}_{4}$ acids. On the other hand, ensuring good reproducibility of nanostructures using stain etching solution can be difficult, several ideas, such as utilizing a stronger etchant type [19], were found be an effective approach including fluoroboric $\left(\mathrm{HBF}_{4}\right)$, hexafluoro silicic $\left(\mathrm{H}_{2} \mathrm{SiF}_{6}\right)$, hexafluoro antimonic $\left(\mathrm{HSbF}_{6}\right)$, hexafluoro titanic $\left(\mathrm{H}_{2} \mathrm{TiF}_{6}\right)$ acids. Despite the efficacy of the chemical stain etching method in the formation of NMs, extreme caution needs to be taken while dealing with HF acid solution and afterward, thus, this drawback can make researchers relatively hesitant to utilizing this method. Yet, the chemical 
4 CHAPTER 1 Liquid-phase synthesis of nanoparticles and nanostructured materials

\begin{tabular}{|c|c|}
\hline Surfactants & Refs. \\
\hline $\begin{array}{l}\text { OEGAE } \\
\text { Span80 } \\
\text { MG } \\
\text { DG } \\
\text { OLA } \\
\text { UDA } \\
\text { CTAB } \\
\text { SDS }\end{array}$ & {$[17,18]$} \\
\hline \multicolumn{2}{|c|}{$\begin{array}{l}\text { CTAB, Cetyltrimethylammonium bromide; DG, diglyceride; MG, monoglyceride; OA, oleyl alcohol, } \\
\text { OEGAE, oleyl ether glycolic acid ethoxylate; SDS, sodium dodecyl sulfate; Span80, sorbitan } \\
\text { monooleate; UDA, undecylenic acid. }\end{array}$} \\
\hline
\end{tabular}

stain etching method in fluoride solutions can be performed at room temperature under indoor light illumination or the UV irradiation [20]. Therefore, this method still seems to be appreciated due to yielding mass scale production of hydride and/or fluoride terminated NMs with narrow size distribution particularly when there are no replacements [21].

\section{ELECTRODEPOSITION METHODS}

Electrodeposition method, also known as electroplating, is an electric current driving deposition method gives a precise control of coating the species epitaxially in the form of NPs, nanowires, and so on, onto a conductive target material [22]. Electrodeposition is referred either to electroplating or to electrophoretic deposition (EPD). The electroplating process is usually based on an aqueous solution of ionic species while EPD occurs in a suspension of particles. In electroplating, there is a charge transfer during the deposition to produce the metal or oxide layer in the electrode. In other words, positively charged ions in the electrolytic solution is reduced upon an external electric field applied so that they could be deposited onto a target material (cathode). In the EPD, deposition occurs without any chemical reaction involved (reduction) (Fig. 1.3). In fact, the principal driving force for EPD is the charge and the electrophoretic mobility of the positively charged particles in the solvent under the influence of an applied electric field, where the solvent should be organic in order to avoid water electrolysis. Another type of the electrochemical deposition is the electroless (autocatalytic) deposition in the presence of a reducing agent (dissolved in the electrolyte), which acts as the electron source for the redox reaction, and no external power supply is used [23]. 

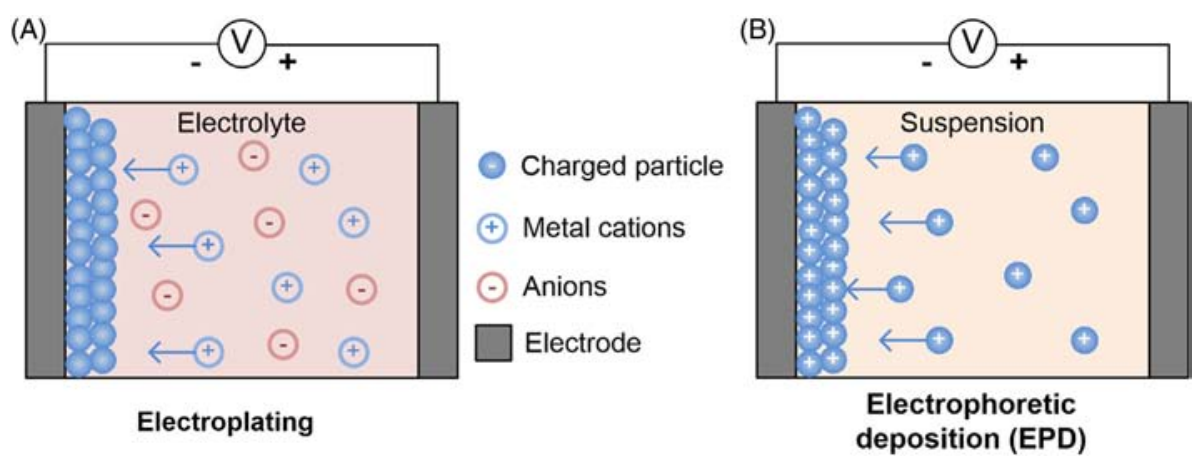

FIGURE 1.3 Two types of electrodeposition processes. (A) Electroplating and (B) electrophoretic deposition (EPD) are schematically demonstrated. (From Santos, L., Neto, J.P., Crespo, A., Baião, P., Barquinha, P., Pereira, L., Martins, R., Fortunato, E., 2015. Electrodeposition of W03 Nanoparticles for Sensing Applications. In: Electroplating of Nanostructures. InTech. under the (C BY 4.0 license).

In general, the process of electrodepositing may be either: (1) an anodic process, where a metal anode is electrochemically oxidized in the solution, react together, and then deposit on the anode; or (2) a cathodic process, where components (ions, clusters, or NPs) are deposited onto the cathode from solution precursors. Film thickness could be controlled by the electrodeposition time, since increasing the reaction time would cause more source material to be consumed and yield larger film thickness. The deposition rate can be followed by the variation of the current with time. Electrodeposition has three advantages over other liquid-phase and gas-phase deposition techniques: (1) allow growing functional NPs through complex 3D nanotemplates. Nanostructures and thin films can be deposited onto large specimen areas of complex shape, making the process highly suitable for industrial use. For example, electrodeposition can be performed within a nanoporous membrane, which serves to act as a template for NPs growth; (2) applicable at room temperature from water-based electrolytes; and (3) suitable to scaled down to the deposition of a few atoms or up to large dimensions, films thickness could range from a $1 \mathrm{~nm}$ to 10 microns. Deposition temperature and current density for the fabrication of metal NPs on semiconductor substrates [24] were also shown to affect the deposition thickness.

To date, three different electrodeposition methods, including potentiostatic technique, galvanostatic technique, and pulse-plating techniques, were experimentally designated. In the potentiostatic technique, current density is changed under constant potential. In galvanostatic technique, electrode potential is varied with a constant current. In pulse-plating technique, the variation of pulse amplitude (e.g., $5 \mathrm{~V}, 10 \mathrm{~V}$ ) and/or pulse width (from ns to 
$\mu \mathrm{s})$ could be studied. When studying with electrodeposition methods, it is also common to refer to the method depending on the forms of the voltammetry. Potential-step electrolysis method $[25,26]$ and cyclic voltammetric technique [27] are such examples used to deposit Au NPs on substrates having a low electrical resistance, such as glassy carbon electrodes. In potential-step electrolysis, applied voltage is increased from $V_{1}$ to $V_{2}$ at some time and current is measured over time. In cyclic voltammetric technique, the potential is swept back-and-forth between $\mathrm{V}_{1}$ to $\mathrm{V}_{2}$ and response on cyclic voltammograms (I-V) are studied in different experimental conditions (e.g., effect of impurities in electrolytes, their concentrations, and temperature). Multilayered NMs are prepared by pulsing or cycling the applied current or potential in a solution containing a mixture of precursors. The potential during the pulse determines the species deposited while the thickness of individual layers is determined by the charge passed. Alternatively, the substrate can be transferred periodically from one electrolytic cell to another.

One of the early examples of the nanostructured materials fabricated via the electrodeposition method was shown for a Ni-Cu alloy in 1987 [28]. Since then, several metallic NMs including Au, Ag, Ni, Co, Fe, and Pt, were achieved by the electrodeposition methods [22]. Electrodeposition methods could also be used to decorate the conductive polymers onto nanostructured materials. For example, the conductive polymers were deposited onto the CNTs for sensing the glucose molecules [29-31]. Electrodeposition methods were also reviewed for the applications of advanced ceramic materials and ceramic coatings [32].

\section{DIRECT-PRECIPITATION METHODS}

Direct-precipitation methods are used for precipitation of NPs within a continuous fluid solvent. Metal salts, such as chloride, nitride, and so on, are dissolved in water. Metal cations exist in the form of metal hydrate species, for example, $\mathrm{Al}\left(\mathrm{H}_{2} \mathrm{O}\right)^{3+}$ or $\mathrm{Fe}\left(\mathrm{H}_{2} \mathrm{O}_{6}\right)^{3+}$. These hydrates are added with basic solutions, such as $\mathrm{NaOH}$ or $\mathrm{NH}_{4} \mathrm{OH}$. $\mathrm{CaCO}_{3}$ particles of different sizes and morphologies can be produced by either mechanical (milling) or chemical routes [33]. The mechanical route often produces a mixture of vaterite, aragonite, and calcite and requires a long processing time to reduce the particle size below $1 \mu \mathrm{m}$. The chemical route has a lower energy consumption and gives better control over the product characteristics and purity. The precipitation conditions, such as the $\left[\mathrm{Ca}^{2+}\right] /\left[\mathrm{CO}_{3}^{2-}\right]$ ratio, $\mathrm{pH}$, temperature, and presence of inorganic/organic additives, are the most important reaction factors $[34,35]$. The control of these key parameters allows for preparing $\mathrm{CaCO}_{3}$ particles with sizes ranging from $50 \mathrm{~nm}$ to a few microns [36]. 
Table 1.2 An Example of the Experimental Procedure Is Demonstrated for the Formation of $\mathrm{Fe}_{3} \mathrm{O}_{4} \mathrm{NPs}$ by the Coprecipitation Method [38]

\begin{tabular}{|lll|} 
Steps & Solution I & Solution II \\
I & $\mathrm{FeCl}_{2} \cdot 4 \mathrm{H}_{2} \mathrm{O}+\mathrm{FeCl}_{3} \cdot 7 \mathrm{H}_{2} \mathrm{O}$ & $\mathrm{NaOH}$ solution \\
II & Surfactant (ammonium oleate) & \\
III & Precursor solution I & Precursor solution II \\
IV & As-prepared $\mathrm{Fe}_{3} \mathrm{O}_{4} \mathrm{NPs}$ & \\
V & Washing & \\
VI & Redispersion in surfactant solution & \\
VII & Recovery of $\mathrm{Fe}_{3} \mathrm{O}_{4} \mathrm{NPs}$ & \\
\hline
\end{tabular}

Coprecipitation is a facile synthesis method generally reported for formation magnetic NPs and nanocomposites at low temperatures. The experimental parameters, including solution $\mathrm{pH}$, reaction temperature, stirring rate, solute, and surfactant concentration, give control on the formation of uniform, spherical, and high-purity NPs [37]. Since 1996, more than one-third of published studies (469 out of 1123) found in Scopus on the formation of NPs by coprecipitation methods include the synthesis of $\mathrm{Fe}_{3} \mathrm{O}_{4}$ NPs in various forms. The synthesis steps of the $\mathrm{Fe}_{3} \mathrm{O}_{4}$ NPs using the coprecipitation method are demonstrated in Table 1.2.

Coprecipitation method also gives an opportunity to alter the surface of NPs in a fast-postsynthesis procedure. Oleic acid modified $\mathrm{Fe}_{3} \mathrm{O}_{4}$ NPs were prepared by the coprecipitation method and their surface changed with DMSA in one step after the synthesis and obtained DMSA-coated $\mathrm{Fe}_{3} \mathrm{O}_{4}$ NPs [39]. Other examples of nanostructured materials prepared by coprecipitation method are PEG-coated $\mathrm{Fe}_{3} \mathrm{O}_{4}$ NPs [40], Ni-Zn-Fe NPs [41], $\mathrm{CoFe}_{2} \mathrm{O}_{4}$ NPs [42], Mn-doped ZnO NPs [43], and $\mathrm{SiO}_{2}$ NPs-polymer composites [44]. The coprecipitation method could also be modified with an external alternating-current magnetic field [45], electric field, microwave or ultrasonic irradiation [46].

\section{SOL-GEL METHODS}

The sol-gel process, involves the evolution of inorganic networks through the formation of a colloidal suspension (sol). The gel can be considered as a solid macromolecule immersed in a solvent. Gelation of the sol to form a network in a continuous liquid-phase (gel). The sol-gel process consists in the chemical transformation of the sol solution into a gel and with subsequent posttreatment and transition into solid oxide material. The sol-gel method is utilized since the 19th century to obtain materials usually for 
inorganics and ceramics either matrix-free or embedded in a matrix. The history of sol-gel methods goes back to 1640 where Van Helmont precipitated $\mathrm{SiO}_{2}$ upon acidifying an alkaline silicate solution. In 1846, Ebelmen developed a transparent glassy material by exposure of silane prepared from $\mathrm{SiCl}_{4}$ and ethanol to the atmosphere [47]. However, the term "sol-gel" was proposed by Graham in 1864 during his work on silica sols [48]. More recently, uniform submicron and nanosilica particles are produced. Stöber et al. [48a] reported a pioneering method for the synthesis of spherical and monodisperse $\mathrm{SiO}_{2}$ particles ranging from $50 \mathrm{~nm}$ to $1 \mathrm{~mm}$ with a narrow size distribution by hydrolysis of an alkylorthosilicate using a mixture of water, alcohol, and ammonia as catalyst [49]. Nowadays, sol-gel technique is a common technology for fabrication of ultrafine powders, monolithic ceramics and glasses, ceramic fibers, inorganic membranes, aerogels, and other types of materials. This method was first applied in 1990 for the formation of nanoporous silica-titania films [50]. Since then, just via small changes in the experimental conditions, the method has evolved and NPs can be obtained in different nanostructured forms [51].

Sol-gel technique is one of the most popular solutions processing for NPs (mostly oxides) production. Formation of freestanding and colloidally stable metal oxide NPs concisely includes [52]: (1) hydrolysis of metal ions $\left(\mathrm{M}^{+\mathrm{y}}\right)$ forming $\mathrm{M}(\mathrm{OH})_{x}$; (2) condensation of $\mathrm{M}(\mathrm{OH})_{x}$ forming stable molecular clusters with oxo (M-O-M) or hydroxo (M-OH-M) bridges and generation of $\mathrm{H}_{2} \mathrm{O}$ as a by-product [51]; (3) growth of the nuclei by addition of reactive species $(\mathrm{M}(\mathrm{OH}) \mathrm{x}$ and clusters) available in the solution on the surface of the nuclei, forming colloidal sol NPs [53]; (4) coagulation of the MOx sol NPs by surface condensation reaction forming a rigid and porous inorganic network enclosing a continuous water phase, the "gel" [51]; (5) evaporation of the solvent and drying the gel via heat treatment or syneresis. Drying of the produced gel at $100^{\circ} \mathrm{C}$ results in a significant amount of shrinkage, densification, and formation of dry hard aggregates (xerogel); and (6) additional heat treatment in a reducing atmosphere, such as $\mathrm{H}_{2} \mathrm{O}$ gas medium for removal of oxides and formation of NMs embedded in a matrix. Controlled calcination of the xerogel at $500^{\circ} \mathrm{C}$ forming a porous structure, while the extensive heating usually from 400 to $700^{\circ} \mathrm{C}$ forms monodispersed NPs. In the sol-gel method, precursors and their concentrations are carefully chosen in order to determine the desired NMs formation and surrounding matrix. For example, the same precursor with different concentrations could be used for controlling the size of NPs.

Using the sol-gel method, various NMs become available in mass-production, including group 14 semiconductor nanocrystals [54], $\mathrm{TiO}_{2} \mathrm{NPs}$ from a different precursor [55] with various morphologies [56], and different dopants [57,58] were prepared by sol-gel method. Magnetic $\mathrm{SrFe}_{12} \mathrm{O}_{19} \mathrm{NPs}$ with controllable morphologies [59], magnetic ferric oxide $\left(\mathrm{Fe}_{2} \mathrm{O}_{3}\right)$ NPs 
[60], $\mathrm{LiFePO}_{4} \mathrm{NPs}^{261]}$ as a cathode material, $\mathrm{XCuZn}$ ferrite NPs (where $\mathrm{X}=\mathrm{Ni}$ [62] or $\mathrm{Mg}$ [63]), $\mathrm{Fe}_{2} \mathrm{O}_{3} / \mathrm{Al}$ nanocomposites [64].

Depending on the application, the final product can be obtained in NPs, nanofibers, or coatings, such as thin film [65].

The most common applications of sol-gel process is the fabrication of various coatings and films are: (1) dip-coating: the substrate is immersed into a sol solution and then withdrawn with a well-defined speed under controlled temperature and atmospheric conditions [66]. Electrochemical sensors, such as CNTs-coated electrodes [67], could be formed using a dip-coating despite the risk of agglomeration of NMs at the surface of coated material. An additional heat treatment after dip-coating might be required to obtain more dense coating. (2) Spin coating: sol solution is poured over the surface of flat substrate and spun off to leave a uniform coating layer on the substrate. Some industrial examples are photoresist coating and compact disc recordable (CD-R) and could be also used to obtain NPs assembled onto the surface of the substrate [68]. Furthermore, freestanding nanostructures are available and could be prepared via layer-by-layer (LBL) assembly using spin coating [69]. (3) Spray coating: sol solutions are sprayed over the surface of flat substrate. Fig. 1.4 shows a schematic representation of the

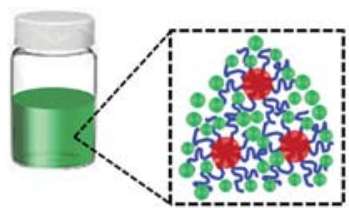

(A) $\mathrm{ZnO}$ sol

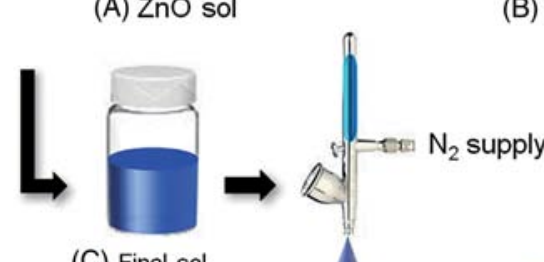

(C) Final sol

(D) Spray deposition

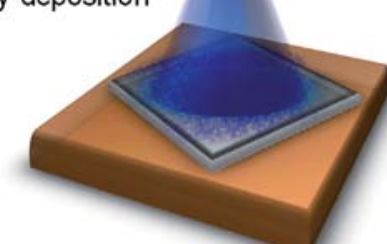

Sample temperature: $80^{\circ} \mathrm{C}$

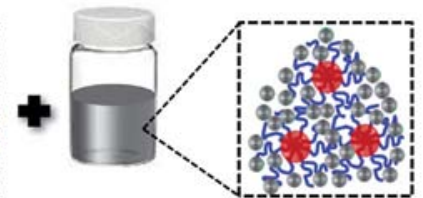

(B) $\mathrm{TiO}_{2}$ sol

(E) Spray-deposited hybrid film

(F) Zinc titanate film

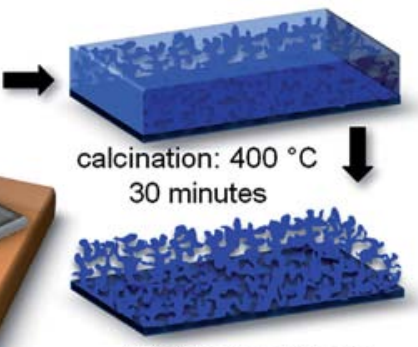

FIGURE 1.4 The steps for the formation of a nanostructured zinc titanate film via sol-gel route, which utilize an amphiphilic diblock copolymer, poly(styrene-block-ethylene oxide) $\mathrm{P}(\mathrm{S}-\mathrm{b}-\mathrm{E} \mathrm{O})$, as the structure-directing template are schematically represented.

(A) The $\mathrm{ZnO}$ sol preparation when zinc acetate dihydrate used as the precursor, (B) the Ti02 sol preparation when ethylene glycol-modified titanate used as the precursor, (C) the two sols are mixed together to obtain the final zinc titanate sol, (D) spray deposition of zinc titanate sol is given, (E) zinc titanate hybrid film is given after the spray-deposition step, (F) the final step includes a calcination process to take away the polymer template resulting in pure nanostructured film. (From The Royal Society of Chemistry; Sarkar, K., Braden, E. V., Fröschl, T., Hüsing, N., Müller-Buschbaum, P., 2014. Spraydeposited zinc titanate films obtained via sol-gel synthesis for application in dye-sensitized solar cells. J. Mater. (hem. A 2, 15008-15014). 
10 CHAPTER 1 Liquid-phase synthesis of nanoparticles and nanostructured materials

multistep process involved in producing $\mathrm{Zn}_{2} \mathrm{TiO}_{4}$ nanostructures via a template-assisted sol-gel route [70]. (4) Flow coating: the liquid coating system is poured over the substrate to be coated. The coating thickness depends on the angle of inclination of the substrate, viscosity of the coating liquid and solvent evaporation rate [71]. NP assemblies in large scales [71,72] can be formed with both parallel and crossed stripe patterns. The velocity profile of the substrate (present on a translated stage) controls the spacing between NPs. (5) Capillary coating: a tubular dispense unit is moved under the substrate surface without physical contact. A spontaneous meniscus is created between the top of the slot tube (or porous cylinder) and the substrate surface, and achieving laminar deposition with high uniformity [73]. Using this method, various NMs-based capillary coating studies [74] were demonstrated including CNTs, graphene, metallic NPs, and magnetic NPs. (6) Roll coating: a thin liquid film of sol solution is uniformly formed on a continuously moving substrate by using rotating rolls [68]. This technique could be combined with liquid flame spray method to have nanostructured coatings $[75,76]$ with $10-50 \mathrm{~nm}$ coating thicknesses. (7) Electrospinning: nanofibers are produced using an electric force to draw charged threads of gel solutions. Then, these nanofibers would move and reach to a lower potential collector plate. Solution parameters, including molecular weight, solution viscosity, solution conductivity; environmental parameters, such as temperature, humidity; and processing parameters, such as voltage, flow rate, the morphology of collector and tip-collector distance would influence the morphology of nanofibers [77]. The research progress on nanofibers using electrospinning were demonstrated for applications in nanomedicine [78] and Li-ion battery separators [79] with properties, such as large surface area and high porosity yielding high loading capacity, high encapsulation efficiency, and low preparation cost.

Overall, the sol-gel method could be utilized for obtaining NPs and nanostructures with various sizes and shapes for the desired physical and chemical properties, however, the reaction time and heat treatment processes are generally long, and thus, a high operational cost could be a challenge.

\section{COLLOIDAL SYNTHESIS METHODS}

Colloidal synthesis methods are simple and well-established wet chemistry precipitation processes in which solutions of the different ions are mixed under controlled temperature and pressure to form colloidal suspensions or insoluble precipitates. Colloidal synthesis is the quickest wet synthesis methods to create colloidal suspensions is by using the aqueous reduction of soluble metallic complexes [80]. The scientific investigations of colloidal 
synthesis methods started only in 1857 when Faraday has published results of his experiments with Au NPs. Faraday prepared Au colloids by reduction of $\mathrm{HAuCl}_{4}$ with phosphorus. Today, colloidal processes are widely used to produce such NMs like metals, metal oxides, organics, and pharmaceuticals. Metallic colloidal NPs are prepared by mixing of few chemicals including a precursor, solvents, a reducing agent, and a surfactant. As a source of NPs at a certain size, the type of precursors are chosen in a particular concentration. The solvents are used to dissolve the precursor and become the solution. Then, a surfactant is included to prevent agglomeration of the NPs when the formation of NPs starts. Finally, the reducing agent is added into this solution to initiate the reaction for formation of NPs.

The synthesized NPs have very high surface energies and will tend to agglomerate and form larger structures to reduce their surface energy. To prevent NPs aggregation and maintain a stable colloidal solution, a stabilizer "capping agent" in the form of a surfactant or an organic polymer is added to restrict particle growth and stop interparticle agglomeration. Therefore, the correct combination of metal concentration and stabilizer (capping agent) will efficiently produce monodispersed metallic NPs. Furthermore, to improve the output from this type of reaction process, various metallic complex precursors, reductants, and different growth media are available. Moreover, even using a two-step reaction instead of a single-step reaction can produce different types of NPs from the same initial raw materials. For example, a two-step reaction involving hydrolysis of an alkoxide followed by reduction to metallic Ge was demonstrated for the fabrication of germanium inverse opals from a colloidal template [81].

The high quality of NPs here can be discussed in combination with their high-colloidal stability, high-quantum yield, high-surface stability, high photostability, and/or high-magnetic saturation. The equipment used in the colloidal synthesis can indeed be cost-effective to prepare such high-quality NPs. Sometimes, the solution prepared from a precursor, a solvent, and a surfactant can be prepared within a syringe added by a syringe pump into a beaker where a reducing agent resides. These conditions are subsequently led from minutes to a few hours to nucleation and growth of inorganic NPs with an option of capping with organic ligands.

Occasionally, NPs can also be prepared with hydrogen termination on their surface, which can be stable for some time at the ambient atmospheric environment. The heat treatment or high pressure inserted into the reaction and its rate can be important and even required in some cases for making NPs in crystalline form, which are so-called colloidal nanocrystals. In most of the studies, the size of NPs is found to be dependent on the concentration 
12 CHAPTER 1 Liquid-phase synthesis of nanoparticles and nanostructured materials

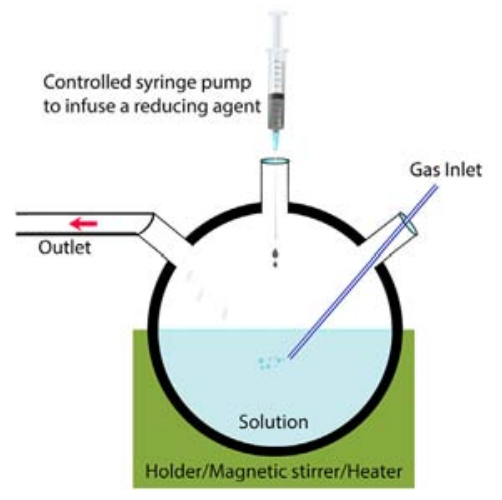

FIGURE 1.5 A schematic of the hotinjection synthesis method. and the type of surfactants, the reaction temperature, and the time required for the formation of NPs. The size of NPs can also be dependent simply on the type of the inert gas used, such as $\mathrm{Ar}$ or $\mathrm{H}_{2}$ Ar used during the purging the reaction solution in order to prevent oxidation of NPs even if all other parameters are the same.

High-quality core/shell nanocrystals can be prepared using colloidal synthesis, including two different layers surrounding one another [82,83]. It is also common to obtain LBL preparation to form colloidal nanocrystals with more than two layers. There are various reasons to choose to increase the number of layers. The first reason is to improve the quantum yield and the second is to terminate the leakage of toxic ions, such as $\mathrm{Cd}^{+2}$ from the core to the ambient environment. There are other effects, such as preparing a "giant" multishell, that would suppress photobleaching and make NPs photostable for a reasonable experimental time, such as about an hour [83]. On the top of such layers, a functionalized surface can also be added for specific purposes, such as for the water solubilization strategies required within biomedical applications [84].

The colloidal chemistry applied to form such NPs includes cases for semiconductors, metal chalcogenides, metallic/metal alloys, and magnetite/hematite NPs. A challenging issue with metallic NPs is to be able to cease the reaction as nucleation/formation of NPs are really rapid. This is important for controlling the size of NPs and reducing the size distribution of NPs. This issue is solved by preparation of small-sized metallic NPs at first, which are then exploited as the seeds of larger NPs.

In the colloidal synthesis of NPs, the hot-injection synthesis and solvothermal methods, including the microwave-assisted method, are subclasses of colloidal synthesis methods. These methods are highlighted one after another henceforth.

\section{HOT-INJECTION SYNTHESIS METHODS}

In the hot-injection synthesis method, the reaction vessel is heated from room temperature to $300^{\circ} \mathrm{C}$ where surfactants are placed in a solvent as schematically demonstrated in Fig. 1.5 so that organic capping agents could bind to the NPs surface to prevent agglomeration of NPs [85]. This process is widely applied because it directly provides colloidal NPs at the end of one-step synthesis.

Table 1.3 shows various examples of NPs prepared using the hot-injection synthesis. In order to avoid the aggregation of NPs and improve their performance, a seed-mediated hot-injection approach to synthesize highly dispersed tiny NPs on a nanosized solid support (Fig. 1.6). This simple, 
Table 1.3 Summary of the Thermolyzes Method Applied for Various NMs

\begin{tabular}{|c|c|c|c|c|c|}
\hline NMs & Precursors & $\begin{array}{l}\text { Solvent or } \\
\text { surfactant }\end{array}$ & $\mathrm{T} /{ }^{\circ} \mathrm{C}$ & $\begin{array}{l}\text { Size range } \\
(\mathrm{nm})\end{array}$ & Refs. \\
\hline $\begin{array}{l}\mathrm{In}_{2} \mathrm{O}_{3^{\prime}} \mathrm{ZnO}, \mathrm{CoO} \\
\mathrm{MnO}\end{array}$ & Metal carboxylate (Ac, Mt, or St) & ODE, OA, or DA & $250-280$ & & [6] \\
\hline $\ln _{2} \mathrm{O}_{3}$ & Indium carboxylate (Ac, Mt, or St) & ODE, DA & $250-290$ & $15-60$ & \\
\hline $\mathrm{Fe}_{3}^{2} \mathrm{O}_{4}^{3}$ & $\mathrm{FeCl}_{3^{\prime}} \mathrm{NaOH}$ & DEG, PAA & 220 & $30-180$ & \\
\hline $\mathrm{PbS}^{3}$ & $\mathrm{~Pb}(\mathrm{Ac})_{2}$, thiourea & DEG, PAA & 215 & $155-240$ & \\
\hline $\mathrm{ZnO}$ & $\mathrm{Zn}(\mathrm{Ac}), \mathrm{NaOH}$ & DEG, PAA & 210 & $60-180$ & \\
\hline $\mathrm{CdE}(\mathrm{E}=\mathrm{S}, \mathrm{Se}, \mathrm{Te})$ & $\mathrm{Me}_{2} \mathrm{Cd}$, (TMS), $\mathrm{S}_{1}(\mathrm{TMS})_{2} \mathrm{Se},(\mathrm{BDMS})_{2} \mathrm{Te}$ & TOP, TOPO & $180-300^{\mathrm{a}}$ & $1.2-11.5$ & [86] \\
\hline & $\mathrm{SiCl}_{4}-\mathrm{I}_{2}-\mathrm{Cl}_{2}-\mathrm{Cl}_{2}$ & TOAB, LAH-THF, ALA & $\mathrm{RT}$ & & \\
\hline $\mathrm{Ge}$ & $\mathrm{GeO}_{2}^{4}$ & EG, PVP, $\mathrm{NaOH}$ & 60 & $2-5$ & {$[87,88]$} \\
\hline $\mathrm{Ge}$ & $\mathrm{GeCl}_{4}^{2}$ & EG, PVP, triglyme & $\mathrm{RT}$ & $3-20$ & {$[89,90]$} \\
\hline C & $\gamma-B T L$ & $\mathrm{CSA}, \mathrm{NCO}, \mathrm{H}_{2} \mathrm{O}$ & 100 & $20-30$ & [91] \\
\hline GeTe & $\mathrm{Gel}_{2}$ & -TOP, TOPO & 250 & $2.5-4.5$ & [92] \\
\hline $\mathrm{Au}$ & $\mathrm{HAuCl}_{4}^{2}$ & MSG, $\mathrm{NaOH}$ & $\geq 254$ & $17-53$ & [93] \\
\hline \multicolumn{6}{|c|}{ 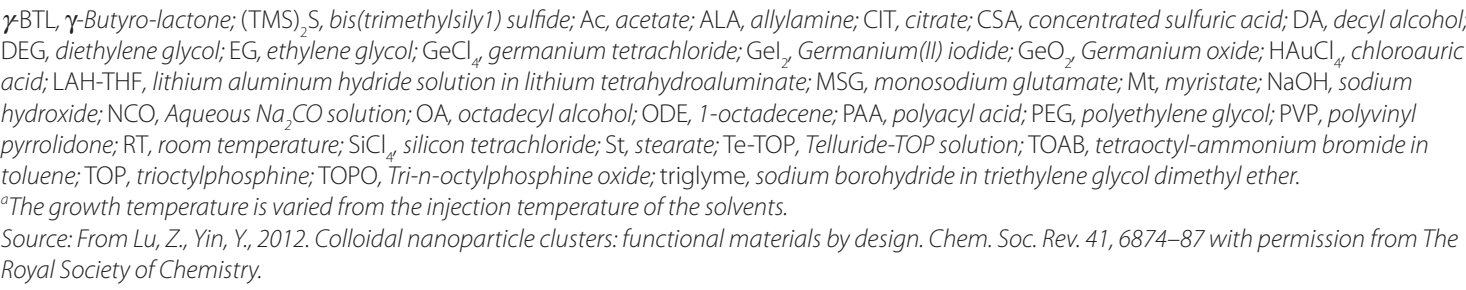 } \\
\hline
\end{tabular}

low-cost, and effective chemical approach allows for synthesizing highly uniform metal NPs $(\sim 10 \mathrm{~nm})$ on the surface of nanoscale solid support without aggregation of the metal NPs. In some cases, in order to lead a homogeneous heat treatment over the reaction, the microwave is operated
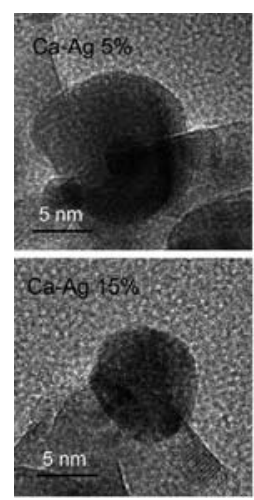
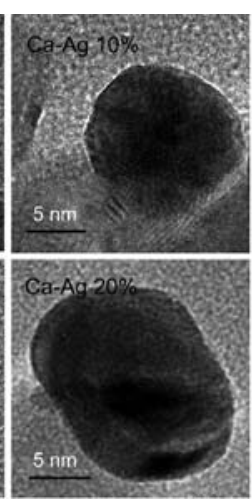
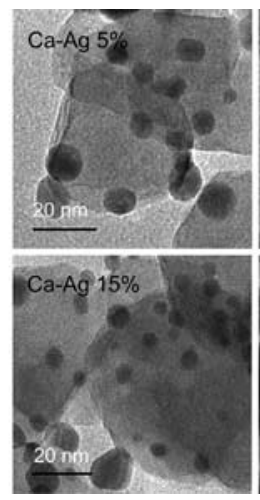
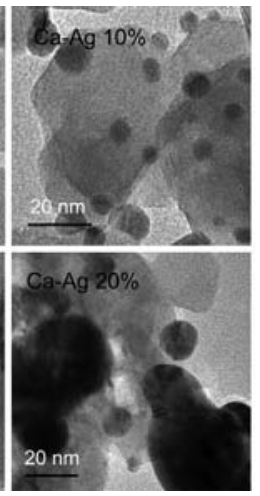
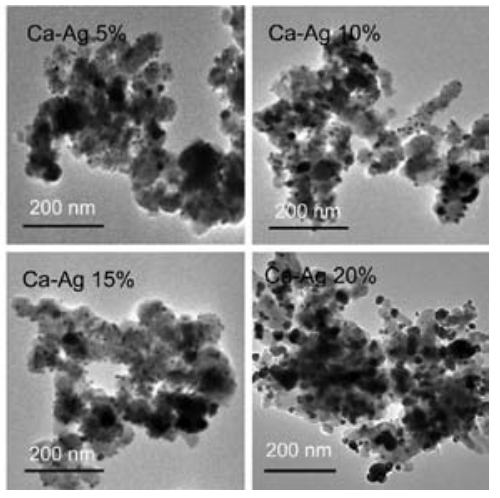

- FIGURE 1.6 TEM images at different magnifications for tiny Ag NPs on CaC03 as a nanoscale solid support. (From Barhoum, A., Rehan, M., Rahier, H., Bechelany, M., Van Assche, G., 2016. Seed-mediated hot-injection synthesis of tiny Ag nanocrystals on nanoscale solid supports and reaction mechanism. ACS Appl. Mater. Interfaces 8, 10551-10561. Copyright 2016 American Chemical Society). 
14 CHAPTER 1 Liquid-phase synthesis of nanoparticles and nanostructured materials

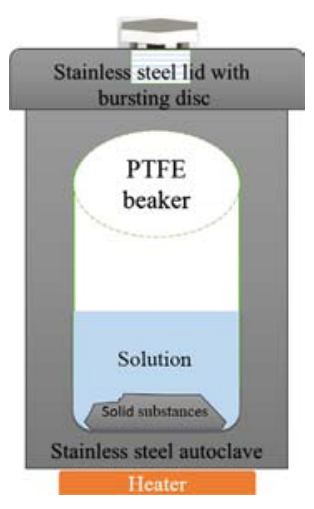

FIGURE 1.7 A schematic of conventional hydrothermal/solvothermal methods. instead of conventional heating. This method is known as microwave-assisted (colloidal) synthesis methods and will be given separately.

\section{HYDROTHERMAL AND SOLVOTHERMAL METHODS}

In the hydrothermal/solvothermal methods, the reaction is heated over the boiling points of precursors. As schematically shown in Fig. 1.7, the reaction for the formation of NPs is generally performed in a closed steel autoclave, therefore, the relationship between temperature, volume, and pressure in the vessel must be considered before initiating the synthesis. Some examples of NPs formed using hydrothermal/solvothermal methods are given in Table 1.4.

The chemical composition of the precursors and the selection of the solvent at optimum temperatures and pressures lead to NPs with various sizes and shapes. Water, as a solvent, for example, is one of the greenest solvents available, which would show anomalous behaviors when approaching the critical point where $\mathrm{T}=374^{\circ} \mathrm{C}$ and $\mathrm{P}=22.4 \mathrm{MPa}$. This information can play role in the creation of the different reactor designs for the synthesis of NPs, including that used in the continuous flow hydrothermal synthesis of metal oxides in supercritical water [96].

\section{MICROWAVE-ASSISTED SYNTHESIS METHODS}

Microwave-assisted methods have been widely applied in chemical reactions and synthesis of NPs and nanostructures. It is an attractive choice to promote reactions and is energy-effective heating compared to conventional

\begin{tabular}{|c|c|c|c|c|c|}
\hline NMs & Precursors & Solvent or surfactant & $\mathrm{T} /{ }^{\circ} \mathrm{C}$ & Size Range/nm & Refs. \\
\hline \multirow{8}{*}{ 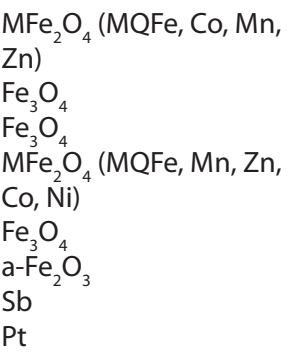 } & $\mathrm{FeCl}_{3^{\prime}} \mathrm{MCl}_{2^{\prime}} \mathrm{NaAC}$ & EG, PEG & 200 & $200-800$ & [6] \\
\hline & $\mathrm{Fe}(\mathrm{acac})_{3}$ & EG, PVP & $140-145$ & $50-100$ & \\
\hline & $\mathrm{FeCl}_{3^{\prime}} \mathrm{NaAC}$ & EG, DEG, sodium acrylate & 200 & $6-170$ & \\
\hline & $\mathrm{FeCl}_{3^{\prime}}, \mathrm{MCl}_{2^{\prime}} \mathrm{NaAC}$ & EG, DEG, PVP & 200 & $20-300$ & \\
\hline & $\mathrm{FeCl}_{3^{\prime}} \mathrm{NaAC}$ & $\mathrm{EG}, \mathrm{Na}_{3} \mathrm{Cit}$ & 200 & $170-300$ & \\
\hline & $\mathrm{FeCl}_{3}$, urea & THF, ethanol, PVP & 180 & & \\
\hline & $\mathrm{Sb}\left(\mathrm{NMe}_{2}\right)_{3}$ & TOP, OLA & $150-200$ & $10-20$ & [94] \\
\hline & $\mathrm{K}_{2} \mathrm{PtCl}_{6}$ & $\mathrm{Na}_{3} \mathrm{Cit}_{2} \mathrm{H}_{2} \mathrm{O}$ & $\geq 250$ & 34 & [95] \\
\hline \multicolumn{6}{|c|}{$\begin{array}{l}\mathrm{CIT} \text {, citrate; DEG, diethylene glycol; EG, ethylene glycol; } \mathrm{K}_{2} \text { PtCl, potassium hexachloroplatinate (IV); OLA, oleylamine; PEG, polyethylene glycol; PVP, } \\
\text { polyvinyl pyrrolidone; TOP, triocty/phosphine. } \\
\text { Source: From Lu, Z, Yin, Y., 2012. Colloidal nanoparticle clusters: functional materials by design. Chem. Soc. Rev. 41, 6874-87 with permission from The } \\
\text { Royal Society of Chemistry. }\end{array}$} \\
\hline
\end{tabular}


heat conduction methods (such as an oil bath) due to the direct heating of the reaction mixture [97].

Microwave heating offers many advantages over conventional heating. Microwaves are a form of electromagnetic radiation with frequencies between $300 \mathrm{MHz}$ and $300 \mathrm{GHz}$ and wavelengths between $1 \mathrm{~m}$ and $1 \mathrm{~mm}$. Nevertheless, in order to prevent interference with telecommunication and radar equipment, it is common for industrial and domestic microwave apparatus to be designed to operate at $2.450 \pm 0.050 \mathrm{GHz}$ (corresponding to $\approx 12.24 \mathrm{~cm}$ in wavelength) [98]. Microwave ovens provide rapid heating compared to conventional conduction and convection heating systems. Microwave has a rapid processing time, 2 to 50 times faster than conventional heating. The rapid heating in this case is caused by the microwaves inducing the fast rotation of dipoles and production of thermal energy, which heats the material [99]. This means that a polar solvent is needed for microwaveassisted synthesis and the higher polarity of solvents will result in the higher generation of the heat upon the microwave irradiation. Polar solvents heat easily throughout the whole volume. This is in direct contrast to the hot plate conventionally used in most liquid-phase synthesis methods, where the thermal energy is transferred by conduction and thermal convections. Nonpolar solvents mixed with small amounts of polar solvents could also be used in the microwave-assisted synthesis of NPs due to the fact that energy transfer between the polar molecules and the nonpolar solvent is rapid. Furthermore, microwave-assisted synthesis is known to produce an increase of the boiling points of organic solvents, which was considered to be due to "nucleate boiling" [100]. To date, various types of microwave reactors specifically designed to perform specific chemical reactions. Generally, a specially designed pressure-rated Teflon-lined vessel is used to contain the reactants to avoid any pressure buildup and possible explosions.

The use of microwaves was first reported by Gedye et al. [101] for rapid organic synthesis, observing the advantages of this technique. Since then, microwaveassisted synthesis of NMs has been found to be promising and combined with other wet-state synthesis methods [98], including microwave autoclave methods, a modified version of the conventional hydrothermal methods; reflux systems; and microwave-assisted nonaqueous sol-gel methods. Some examples of such microwave-assisted synthesis were reported for graphene-containing NMs [102] for lithium-ion batteries. Other examples of microwave-assisted synthesis of NMs include ZnO NPs [103] with different morphologies [104], $\mathrm{Ag}$ NPs [105,106], Cu NPs [107], $\mathrm{Co}_{3} \mathrm{O}_{4}$ NPs [108], composites of metal [109]/ metal oxide [97] NPs supported with CNTs and RE-doped $\mathrm{YPO}_{4}(\mathrm{RE}=\mathrm{Eu}, \mathrm{Ce}$, $\mathrm{Tb}$ and $\mathrm{Ce}+\mathrm{Tb}$ ) nanophosphors [110]. Fig. 1.8 represents a schematic of the production process of $\mathrm{ZnO}$ seed layer and the subsequent synthesis of $\mathrm{ZnO}$ 
16 CHAPTER 1 Liquid-phase synthesis of nanoparticles and nanostructured materials

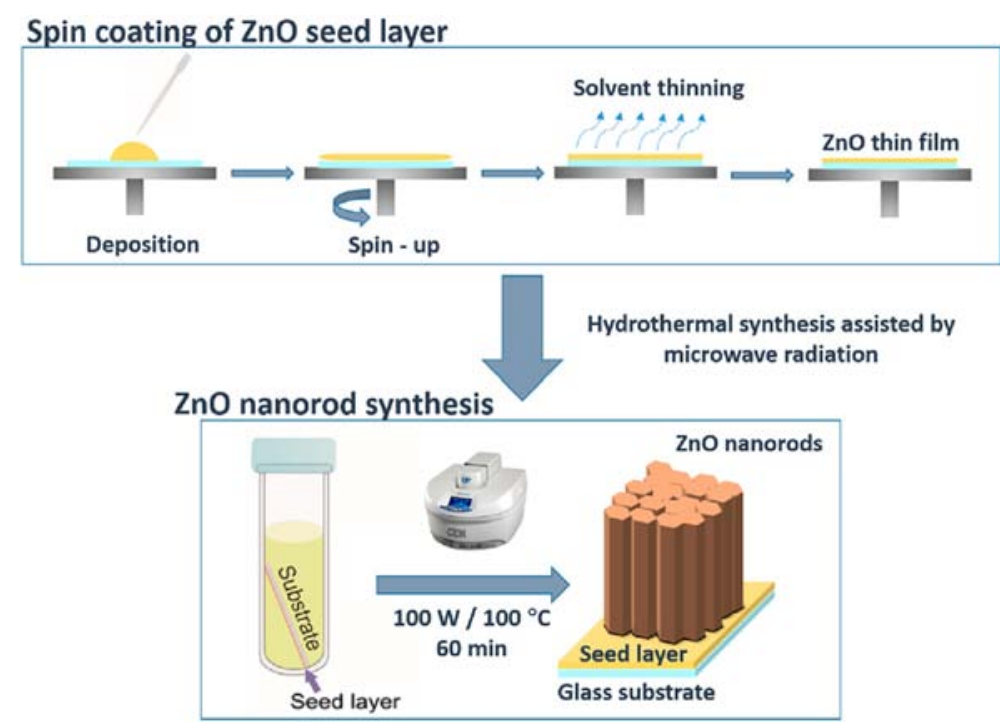

FIGURE 1.8 A schematic of the $\mathrm{Zn0}$ seed layer deposition is demonstrated. The spincoating method is treated first by $\mathrm{Zn} 0$ nanorod arrays. Then, the $\mathrm{Zn} 0$ seed layer deposited substrate was placed in a vial for the hydrothermal method assisted by microwave radiation. (From Pimentel, A., Ferreira, S., Nunes, D., Calmeiro, T., Martins, R., Fortunato, E., 2016. Microwave synthesized ZnO nanorod arrays for uv sensors: a seed layer annealing temperature study. Materials (Basel). 9, 299. under the (C BY 4.0 license).

nanorod arrays. After uniformly coating the glass substrates with $\mathrm{ZnO}$ thin films, $\mathrm{ZnO}$ nanorod arrays were synthesized by hydrothermal method assisted by microwave radiation. The $\mathrm{ZnO}$ seeded substrates were placed at an angle against the vessel, with the seed layer facing down [111].

\section{ULTRASONIC SYNTHESIS METHODS}

Ultrasonic synthesis methods have emerged as a powerful synthesizing technique to prepare NP nanostructured materials. The ultrasound frequency range is above $20 \mathrm{kHz}$ and can reach frequencies in the gigahertz level. By applying the ultrasonic radiation to the precursor solution, the chemical reaction is initiated. As a form of radiation, ultrasound has the capacity to break chemical bonds and create products. The sudden implosion of the bubbles (about $100 \mu \mathrm{m}$ in size) creates a local hot spot, which can reach temperatures as high as $5000 \mathrm{~K}$ and pressures of up to hundreds of atmospheres depending on the level of ultrasound power used. At the same time, the cooling rates are extremely high and can be as great as $10^{11} \mathrm{~K} / \mathrm{s}$ [99]. The capacity of ultrasound to create these extreme 
temperatures and pressures within a medium makes this technique attractive. The ultrasound leads to creation, growth, and rapid collapse of small bubbles, which act as nucleation centers. The growth of nucleus ends after bubble collapse. Size and shape selection in ultrasound synthesis is accomplished by controlling the precursor concentrations, $\mathrm{pH}$, temperature, and surfactant concentration.

Facile synthesis of fuel cell materials containing metallic NPs [112] was demonstrated via ultrasonic synthesis method in the absence and presence of surfactants and alcohols. Nanostructured photocatalysts [113] were also prepared using ultrasonic synthesis method. Recent studies on Ag NPs [106], carbon NPs [114], nanosized MOFs [115,116], silica NPs [117], PdSn NPs [118] also present ultrasonic synthesis method to be promising for the formation of various NPs systems. Besides, ultrasound synthesis methods are used not only for the synthesis of NMs but also for other purposes, such as loading NPs inside nanotubes or surface functionalization of NPs with polymers. Ag NPs-loaded $\mathrm{TiO}_{2}$ nanotubes [119] and Pt NPs-loaded CNTs [120] were demonstrated for loading NPs inside nanotubes via ultrasonication. On the other hand, polymerization [121] has also been known for 30 years to be initiated via ultrasonication. This knowledge was applied, for instance, for the ultrasonic synthesis of iron NPs and their surface stabilization using polymers ([122]; 1998).

Teo et al. have prepared $100 \mathrm{~nm}$ latex beads loaded with a high content of $\mathrm{Fe}_{3} \mathrm{O}_{4}$ NPs via encapsulation of $\mathrm{Fe}_{3} \mathrm{O}_{4}$ NPs with latex beads under the ultrasound-initiated effect is well illustrated in Fig. 1.9. The NPs exhibited excellent colloidal stability and superparamagnetic properties (24 emu/g), and were of the desired size to be technologically relevant [123].

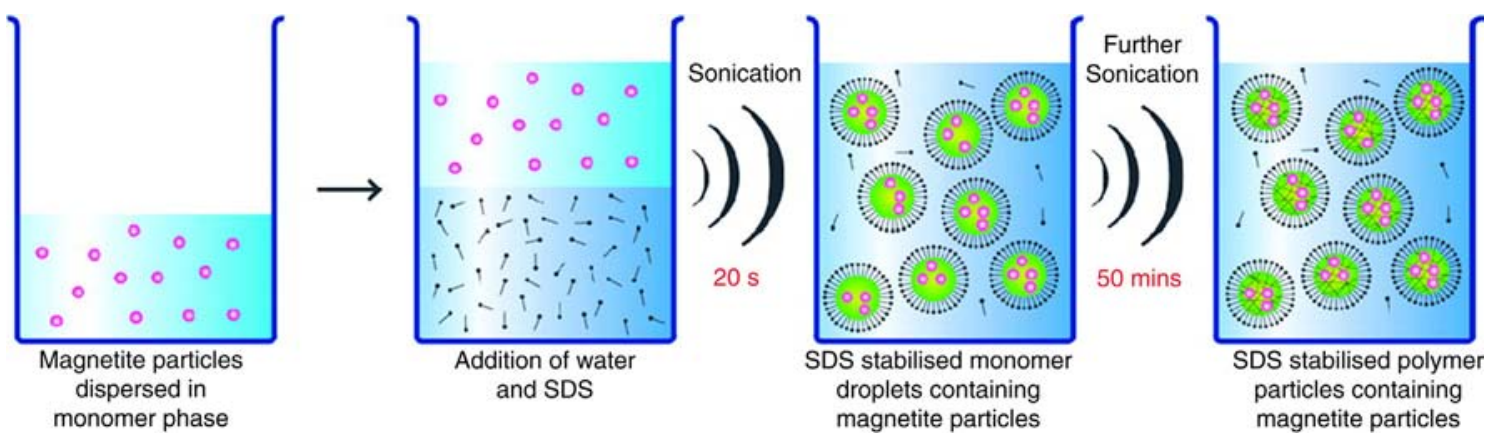

FIGURE 1.9 Encapsulation process of $\mathrm{Fe}_{3} \mathrm{O}_{4}$ NPs through sonochemically driven miniemulsion polymerization of monomer droplet to latex particle is schematically demonstrated. (From Teo, B.M., Chen, F., Hatton, T.A., Grieser, F., Ashokkumar, M., 2009. Novel one-pot synthesis of magnetite latex nanoparticles by ultrasound irradiation. Langmuir 25, 2593-2595. Copyright 2009 American Chemical Society). 
18 CHAPTER 1 Liquid-phase synthesis of nanoparticles and nanostructured materials

\section{LASER ABLATION IN LIQUID-PHASE}

The laser ablation has been operated since the invention of the ruby laser in the 1960s [124]. After the 1980s, a wide range of NMs in ambient conditions [125], in gas [126] or in liquid-phase [127] were become available by this method. The laser ablation in the liquid-phase includes a high power laser, an optical focusing system, a bulk target, and a liquid. The laser beam generally produced by a nano/femtosecond pulsed laser system is directed by the optical components onto the bulk target inside a liquid host as shown in Fig. 1.10.

The laser ablation for synthesis of NPs can happen either in gas or liquid phase. The main differences between ablation in liquids and ablation in gas phase/vacuum that ablation occurs at the boundary between the solid and liquid phase or the solid and the gas, respectively. The laser ablation in liquids is more efficient because the formation and distribution of the plasma plume occurs in the liquid environment, liquids have a much higher thermal conductivity than gas. In general, a large number of chemical transformations are possible in liquid phase, the process mechanisms, aggregate states, and phase transitions depending on the pulse duration in temperature-density coordinates. Fig. 1.10 shows the ablation process and the formation of a plasma cloud (Fig. 1.10A) in the liquid phase.

The first study of the laser ablation in the liquid-phase was performed in 1987 when pure iron in liquid ammonia was ablated for nitridation of iron

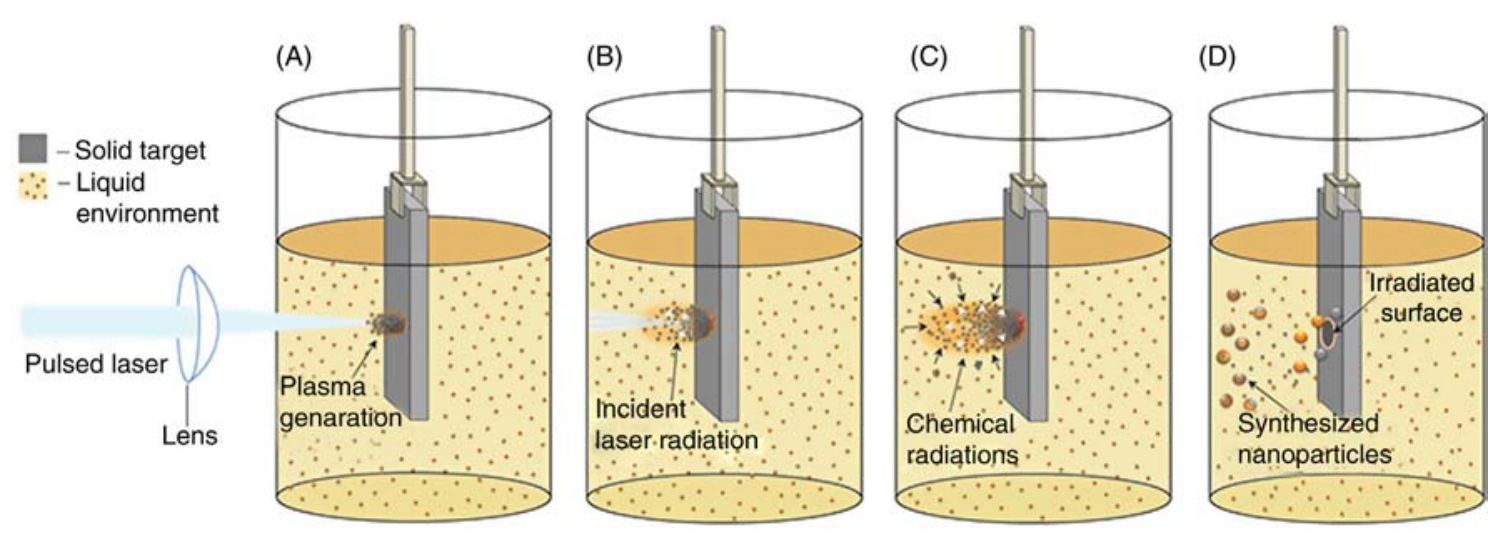

FIGURE 1.10 Laser ablation in liquid-phase is demonstrated using a nanosecond-pulsed laser. (A) Laser pulse is absorbed and a plasma plume is formed, (B) the laser plasma is evolved and interacted with radiation, (C) the plasma is further evolved and the chemical reactions inside the plume and at the border are given, (D) the nanoparticles are formed/diffused in liquid and the substrate surface is eroded. (From: Svetlichnyi, V.A., Shabalina, A.V, Lapin, I.N., Goncharova, D.A., 2016. Metal oxide nanoparticle preparation by pulsed laser ablation of metallic targets in liquid. In: Applications of Laser Ablation Thin Film Deposition, Nanomaterial Synthesis and Surface Modification. InTech. Under the (C BY 4.0 license). 


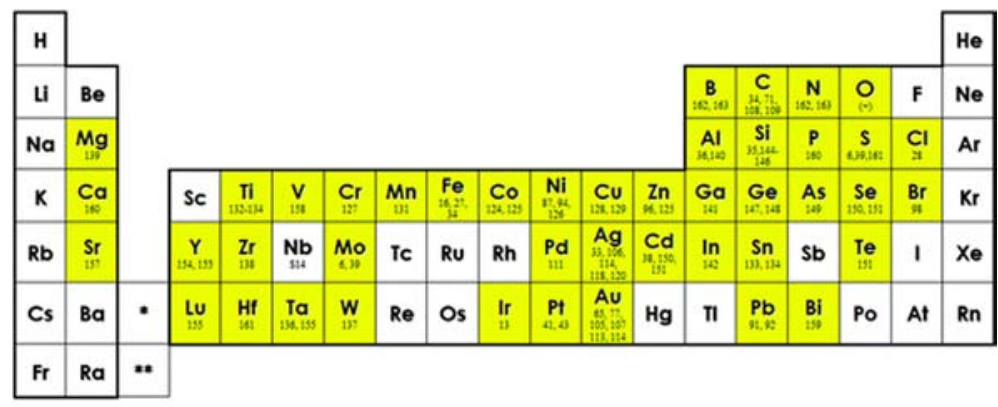

\begin{tabular}{|c|c|c|c|c|c|c|c|c|c|c|c|c|c|c|}
\hline - & La & $\underset{134.196}{\mathrm{Ce}}$ & Pr & Nd & Pm & $\mathrm{Sm}$ & EU & $\underset{18,1}{\mathbf{G d}}$ & Tb & Dy & Ho & Er & Im & $\mathrm{Tb}$ \\
\hline * & $A C$ & Th & $\mathrm{Pa}$ & $\underset{t: S}{U}$ & Np & Pu & Am & $\mathrm{Cm}$ & BK & $\mathrm{Ct}$ & Es & $\mathrm{Fm}$ & Md & No \\
\hline
\end{tabular}

FIGURE 1.11 Summary of NMs formed by laser Ablation in the liquid phase. (Reproduced with permission from the PCCP Owner Societies; Amendola, V., Meneghetti, M., 2013. What controls the composition and the structure of nanomaterials generated by laser ablation in liquid solution? Phys. Chem. Chem. Phys. 15, 3027-46).

[128]. This was later shown successfully to produce photoluminescent silicon NPs [129] with a possibility of tuning their size [127]. These studies were later expanded within various liquid hosts for the formation of $\mathrm{Si}$ and Ge NMs $[127,130,131]$. The examples of the NMs formed from several bulk targets [132] are shown in Fig. 1.11. Here, various liquid hosts were reported, including water, ethanol, acetonitrile, dimethylformamide, tetrahydrofuran, dimethylsulfoxide, and toluene.

Upon the exposure of the laser light onto the bulk target surface, the extreme temperatures and pressures are reached at the target-liquid interface, which may result in the vapor of the solid target with some amounts of the surrounding liquid. In other words, the interaction of the laser light with the bulk target yields an ablation plume [125]. The ablation plume contains very energetic atoms, ions and/or molecules of the bulk material expanding to the environment throughout the liquid host. The liquid host is chosen in a way that it should not be absorbing the laser light and shall interact with NMs for possible surface functionalization. Overall, the colloidal NMs as a product from various bulk targets and the liquid hosts [132] can be formed via the laser ablation in the liquid-phase.

\section{CONCLUSIONS}

We reviewed most of the liquid-phase synthesis methods from a solution of chemical compounds for formation of NPs and nanostructured materials, including developments of the methods for the purpose of low cost, 


\section{CHAPTER 1 Liquid-phase synthesis of nanoparticles and nanostructured materials}

high quality, low toxicity, and desired surface functionality. The liquid-state synthesis methods reviewed here include chemical stain etching, electrodeposition methods, direct-precipitation methods, sol-gel methods, colloidal synthesis methods, hot-injection synthesis methods, hydrothermal and solvothermal methods, microwave-assisted synthesis methods, ultrasonic synthesis methods, and laser ablation in liquid-phase. From the biomedical perspective, such NPs are expected in the near future to be established from noninvasive targeted superresolution imaging applications and clearing NPs from animal/human bodies to therapeutics. On the other hand, new recipes or progress in the synthesis is demanded by electronic industry which requires the use of NMs for specific purposes, such as in composites with reproducible electrical conductivity and boosting the efficiency of rotating electrical machines. Nanostructured materials, including CNTs and nanoporous materials, are the last but not the least examples of near future applications, which are planned to be made optimum for low-cost and large-scale environmental pollution control, including trapping greenhouse emissions and cleaning harmful pollutants in water.

\section{REFERENCES}

[1] A.P. Alivisatos, Semiconductor clusters, nanocrystals, and quantum dots, Science 80 (271) (1996) 933-937.

[2] J. Feng, G. Biskos, A. Schmidt-Ott, Toward industrial scale synthesis of ultrapure singlet nanoparticles with controllable sizes in a continuous gas-phase process, Sci. Rep. 5 (2015) 15788.

[3] A. Gutsch, H. Mühlenweg, M. Krämer, Tailor-made nanoparticles via gas-phase synthesis, Small 1 (2004) 30-46.

[4] C.A. Charitidis, P. Georgiou, M.A. Koklioti, A.-F. Trompeta, V. Markakis, Manufacturing nanomaterials: from research to industry, Manuf. Rev. 1 (2014) 11.

[5] X. Cheng, S.B. Lowe, P.J. Reece, J.J. Gooding, Colloidal silicon quantum dots: from preparation to the modification of self-assembled monolayers (SAMs) for bio-applications, Chem. Soc. Rev. 43 (2014) 2680.

[6] Z. Lu, Y. Yin, Colloidal nanoparticle clusters: functional materials by design, Chem. Soc. Rev. 41 (2012) 6874-6887.

[7] S.-K. Eah, A very large two-dimensional superlattice domain of monodisperse gold nanoparticles by self-assembly, J. Mater. Chem. 21 (2011) 16866.

[8] R.J. Archer, Stain films on silicon, J. Phys. Chem. Solids 14 (1960) 104-110.

[9] C.S. Fuller, J.A. Ditzenberger, Effect of structural defects in germanium on the diffusion and acceptor behavior of copper, J. Appl. Phys. 28 (1957) 40-48.

[10] A.G. Cullis, L.T. Canham, Visible light emission due to quantum size effects in highly porous crystalline silicon, Nature 353 (1991) 335-338.

[11] M.T. Kelly, J.K.M. Chun, A.B. Bocarsly, High efficiency chemical etchant for the formation of luminescent porous silicon, Appl. Phys. Lett. 64 (1994) 1693.

[12] P.G. Abramof, A.F. Beloto, A.Y. Ueta, N.G. Ferreira, X-ray investigation of nanostructured stain-etched porous silicon, J. Appl. Phys. 99 (2006) 24304. 
[13] V. Karavanskii, A. Lomov, A. Sutyrin, V. Bushuev, N. Loikho, N. Melnik, T. Zavaritskaya, S. Bayliss, Raman and X-ray studies of nanocrystals in porous stain-etched germanium, Thin Sol. Films 437 (2003) 290-296.

[14] E. Vazsonyi, E. Szilagyi, P. Petrik, Z.E. Horvath, T. Lohner, M. Fried, G. Jalsovszky, Porous silicon formation by stain etching, Thin Sol. Films 388 (2001) 295-302.

[15] T. Hadjersi, N. Gabouze, E. Kooij, A. Zinine, A. Ababou, W. Chergui, H. Cheraga, S. Belhousse, A. Djeghri, Metal-assisted chemical etching in $\mathrm{HF} / \mathrm{Na}_{2} \mathrm{~S}_{2} \mathrm{O}_{8}$ OR HF/ $\mathrm{KMnO}_{4}$ produces porous silicon, Thin Sol. Films 459 (2004) 271-275.

[16] F.G. Zeng, C.C. Zhu, X.N. Fu, W.W. Wang, Z.M. Zhao, Preparation of co-passivated porous silicon by stain etching, Mater. Chem. Phys. 90 (2005) 310-314.

[17] S. Chattopadhyay, P.W. Bohn, Surfactant-induced modulation of light emission in porous silicon produced by metal-assisted electroless etching, Anal. Chem. 78 (2006) 6058-6064.

[18] V. Chirvony, A. Chyrvonaya, J. Ovejero, E. Matveeva, B. Goller, D. Kovalev, A. Huygens, P. de Witte, Surfactant-modified hydrophilic nanostructured porous silicon for the photosensitized formation of singlet oxygen in water, Adv. Mater. 19 (2007) 2967-2972.

[19] A. Parbukov, V. Beklemyshev, V. Gontar, I. Makhonin, S. Gavrilov, S. Bayliss, The production of a novel stain-etched porous silicon, metallization of the porous surface and application in hydrocarbon sensors, Mater. Sci. Eng. C 15 (2001) 121-123.

[20] K.W. Kolasinski, Etching of silicon in fluoride solutions, Surf. Sci. 603 (2009) 1904-1911.

[21] W. Little, A. Karatutlu, D. Bolmatov, K. Trachenko, A.V. Sapelkin, G. Cibin, R. Taylor, F. Mosselmans, A.J. Dent, G. Mountjoy, Structural origin of light emission in germanium quantum dots, Sci. Rep. 4 (2014) 7372.

[22] U.S. Mohanty, Electrodeposition: a versatile and inexpensive tool for the synthesis of nanoparticles, nanorods, nanowires, and nanoclusters of metals, J. Appl. Electrochem. 41 (2011) 257-270.

[23] L. Santos, J.P. Neto, A. Crespo, P. Baião, P. Barquinha, L. Pereira, R. Martins, E. Fortunato, Electrodeposition of WO3 nanoparticles for sensing applications, Electroplating of Nanostructures, InTech, (2015).

[24] A. Grueb, C.I. Lin, H.L. Hartnagel, Electrolytic deposition techniques for the fabrication of submicron anodes, in: Proceedings of the Sixth Interntional Symposium on Space Terahertz Technology, California Institute of Technology, 1995Pasadena, CA, United States, March 21-23. p. 54.

[25] M.S. El-Deab, On the preferential crystallographic orientation of Au nanoparticles: effect of electrodeposition time, Electrochim. Acta 54 (2009) 3720-3725.

[26] M.S. El-Deab, T. Okajima, T. Ohsaka, Electrochemical reduction of oxygen on gold nanoparticle-electrodeposited glassy carbon electrodes, J. Electrochem. Soc. 150 (2003) A851.

[27] Y. Ma, J. Di, X. Yan, M. Zhao, Z. Lu, Y. Tu, Direct electrodeposition of gold nanoparticles on indium tin oxide surface and its application, Biosens. Bioelectron. 24 (2009) 1480-1483.

[28] J. Yahalom, O. Zadok, Formation of composition-modulated alloys by electrodeposition, J. Mater. Sci. 22 (1987) 499-503.

[29] M. Gao, L. Dai, G.G. Wallace, Biosensors based on aligned carbon nanotubes coated with inherently conducting polymers, Electroanalysis 15 (2003) 1089-1094. 


\section{CHAPTER 1 Liquid-phase synthesis of nanoparticles and nanostructured materials}

[30] M. Gao, S. Huang, L. Dai, G. Wallace, R. Gao, Z. Wang, Aligned coaxial nanowires of carbon nanotubes sheathed with conducting polymers, Angew. Chem. Int. Ed. 39 (2000) 3664-3667.

[31] J.J. Gooding, Nanostructuring electrodes with carbon nanotubes: a review on electrochemistry and applications for sensing, Electrochim. Acta 50 (2005) 3049-3060.

[32] A.R. Boccaccini, I. Zhitomirsky, Application of electrophoretic and electrolytic deposition techniques in ceramics processing - Part 2, InterCeram Int. Ceram. Rev. 54 (2005) 242-246.

[33] S.M. El-Sheikh, A. Barhoum, S. El-Sherbiny, F. Morsy, A.A.-H. El-Midany, H. Rahier, Preparation of superhydrophobic nanocalcite crystals using Box-Behnken design, Arab. J. Chem. (2014).

[34] F.A. Morsy, S.M. El-Sheikh, A. Barhoum, Nano-silica and $\mathrm{SiO}_{2} / \mathrm{CaCO}_{3}$ nanocomposite prepared from semi-burned rice straw ash as modified papermaking fillers, Arab. J. Chem. (2014).

[35] A. Barhoum, G. Van Assche, A.S.H. Makhlouf, H. Terryn, K. Baert, M.-P. Delplancke, S.M. El-Sheikh, H. Rahier, A green simple chemical route for the synthesis of pure nanocalcite crystals, Cryst. Growth Des. 15 (2015) 573-580.

[36] S. El-Sherbiny, S.M. El-Sheikh, A. Barhoum, Preparation and modification of nano calcium carbonate filler from waste marble dust and commercial limestone for papermaking wet end application, Powd. Technol. 279 (2015) 290-300.

[37] D.-S. Bae, K.-S. Han, S.-B. Cho, S.-H. Choi, Synthesis of ultrafine $\mathrm{Fe}_{3} \mathrm{O}_{4}$ powder by glycothermal process, Mater. Lett. 37 (1998) 255-258.

[38] K.T. Wu, P.C. Kuo, Y.D. Yao, E.H. Tsai, Magnetic and optical properties of $\mathrm{Fe}_{3} \mathrm{O}_{4} \backslash$ nanoparticle ferrofluids prepared by coprecipitation technique, IEEE Trans. Magn. 37 (2001) 2651-2653.

[39] S.N. Ball, A. Mishra, A.K. Dutta, P. Sen, International Conference on Recent Trends in Physics (ICRTP 2012), J. Phys. Conf. Ser. 365 (2012) 11001.

[40] M. Anbarasu, M. Anandan, E. Chinnasamy, V. Gopinath, K. Balamurugan, Synthesis and characterization of polyethylene glycol (PEG) coated $\mathrm{Fe}_{3} \mathrm{O}_{4}$ nanoparticles by chemical co-precipitation method for biomedical applications, Spectrochim. Acta A. Mol. Biomol. Spectrosc. 135 (2015) 536-539.

[41] K. Velmurugan, V. Sangli, K. Venkatachalapathy, S. Sendhilnathan, Synthesis of nickel zinc iron nanoparticles by coprecipitation technique, Mater. Res. 13 (2010) 299-303.

[42] Y. Qu, H. Yang, N. Yang, Y. Fan, H. Zhu, G. Zou, The effect of reaction temperature on the particle size, structure and magnetic properties of coprecipitated $\mathrm{CoFe}_{2} \mathrm{O}_{4}$ nanoparticles, Mater. Lett. 60 (2006) 3548-3552.

[43] N. Suganthi, K. Pushpanathan, Paramagnetic nature of Mn doped ZnS nano particles in opto electronic device application, J. Mater. Sci. Mater. Electron. 27 (2016) 10089-10098.

[44] H.Y. Shimomura, Spontaneous formation of silica-polymer composite particles by simple co-precipitation process, Jpn. J. Appl. Phys. 53 (2014) 05FT02.

[45] Y. Li, K. Hu, B. Chen, Y. Liang, F. Fan, J. Sun, Y. Zhang, N. Gu, Fe $\mathrm{O}_{4} @ \mathrm{PSC}$ nanoparticle clusters with enhanced magnetic properties prepared by alternatingcurrent magnetic field assisted co-precipitation, Colloids Surf. A 520 (2017) 348-354.

[46] S. Wu, A. Sun, F. Zhai, J. Wang, W. Xu, Q. Zhang, A.A. Volinsky, $\mathrm{Fe}_{3} \mathrm{O}_{4}$ magnetic nanoparticles synthesis from tailings by ultrasonic chemical co-precipitation, Mater. Lett. 65 (2011) 1882-1884. 
[47] R. Ciriminna, A. Fidalgo, V. Pandarus, F. Béland, L.M. Ilharco, M. Pagliaro, The sol-gel route to advanced silica-based materials and recent applications, Chem. Rev. 113 (2013) 6592-6620.

[48] T. Graham, On the properties of silicic acid and other analogous colloidal substances, J. Chem. Soc. 17 (1864) 318.

[48a] W. Stöber, A. Fink, E. Bohn, Controlled growth of monodisperse silica spheres in the micron size range, J. Colloid Interface Sci. 26 (1968) 62-69.

[49] K.S. Rao, K. El-Hami, T. Kodaki, K. Matsushige, K. Makino, A novel method for synthesis of silica nanoparticles, J. Colloid Inter. Sci. 289 (2005) 125-131.

[50] A.J. Martin, M. Green, in: J.D. Mackenzie, D.R. Ulrich (Eds.), Sol-gel nano-porous silica-titania thin films with liquid fill for optical interferometric sensors, Proc. SOIE 1328, Sol-Gel Optics (1990) November 1.

[51] A.E. Danks, S.R. Hall, Z. Schnepp, The evolution of "sol-gel" chemistry as a technique for materials synthesis, Mater. Horiz. 3 (2016) 91-112.

[52] M. Barczak, C. Mcdonagh, D. Wencel, Micro- and nanostructured sol-gel-based materials for optical chemical sensing (2005-2015), Microchim. Acta 183 (7) (2016) 2085-2109.

[53] D.P. Debecker, V. Hulea, P.H. Mutin, Mesoporous mixed oxide catalysts via nonhydrolytic sol-gel: a review, Appl. Catal. A Gen 451 (2013) 192-206.

[54] J.G.C. Veinot, E.J. Henderson, C.M. Hessel, Sol-gel derived precursors to Group 14 semiconductor nanocrystals: convenient materials for enabling nanocrystal-based applications, IOP Conf. Ser. Mater. Sci. Eng. 6 (2009) 12017.

[55] Z.R. Ismagilov, L.T. Tsikoza, N.V. Shikina, V.F. Zarytova, V.V. Zinoviev, S.N. Zagrebelnyi, Synthesis and stabilization of nano-sized titanium dioxide, Russ. Chem. Rev. 78 (2009) 873-885.

[56] Y. Wang, Y. He, Q. Lai, M. Fan, Review of the progress in preparing nano $\mathrm{TiO}_{2}$ : an important environmental engineering material, J. Environ. Sci. 26 (2014) 2139-2177.

[57] C.M. Malengreaux, S.L. Pirard, G. Léonard, J.G. Mahy, M. Herlitschke, B. Klobes, R. Hermann, B. Heinrichs, J.R. Bartlett, Study of the photocatalytic activity of $\mathrm{Fe}_{3}+, \mathrm{Cr}_{3}+\mathrm{La}_{3}+$ and $\mathrm{Eu}_{3}+$ single-doped and co-doped $\mathrm{TiO}_{2}$ catalysts produced by aqueous sol-gel processing, J. Alloys Comp. 691 (2017) 726-738.

[58] P. Yang, C. Lu, N. Hua, Y. Du, Titanium dioxide nanoparticles co-doped with $\mathrm{Fe}_{3}+$ and $\mathrm{Eu}_{3}+$ ions for photocatalysis, Mater. Lett. 57 (2002) 794-801.

[59] X. Yang, Q. Li, J. Zhao, B. Li, Y. Wang, Preparation and magnetic properties of controllable-morphologies nano-SrFe12O19 particles prepared by sol-gel selfpropagation synthesis, J. Alloys Comp. 475 (2009) 312-315.

[60] L.I. Jun-, W. Yu-, Research progress of the preparation of nano-ferric oxide, Asian J. Chem. 25 (2013) 8-10.

[61] K.-F. Hsu, S.-Y. Tsay, B.-J. Hwang, Synthesis and characterization of nano-sized LiFePO 4 cathode materials prepared by a citric acid-based sol-gel route, J. Mater. Chem. 14 (2004) 2690-2695.

[62] Z. Yue, J. Zhou, L. Li, H. Zhang, Z. Gui, Synthesis of nanocrystalline NiCuZn ferrite powders by sol-gel auto-combustion method, J. Magn. Magn. Mater. 208 (2000) 55-60.

[63] M.R. Barati, Characterization and preparation of nanocrystalline $\mathrm{MgCuZn}$ ferrite powders synthesized by sol-gel auto-combustion method, J. Sol-Gel Sci. Technol. 52 (2009) 171-178. 


\section{CHAPTER 1 Liquid-phase synthesis of nanoparticles and nanostructured materials}

[64] T.M. Tillotson, A.E. Gash, R.L. Simpson, L.W. Hrubesh, J.H. Satcher, J.F. Poco, Nanostructured energetic materials using sol-gel methodologies, J. Non. Cryst. Solids 285 (2001) 338-345.

[65] S.C. Tjong, H. Chen, Nanocrystalline materials and coatings, Mater. Sci. Eng. R. 45 (2004) 1-88.

[66] H. Garg, G. Bedi, A. Garg, Implant surface modifications: a review, J. Clin. Diagn. Res. 6 (2012) 319-324.

[67] C. Yang, M.E. Denno, P. Pyakurel, B.J. Venton, Recent trends in carbon nanomaterial-based electrochemical sensors for biomolecules: a review, Anal. Chim. Acta 887 (2015) 17-37.

[68] S. Maenosono, T. Okubo, Y. Yamaguchi, Overview of nanoparticle array formation by wet coating, J. Nanopart. Res. 5 (2003) 5-15.

[69] C. Jiang, V.V. Tsukruk, Freestanding nanostructures via layer-by-layer assembly, Adv. Mater. 18 (2006) 829-840.

[70] K. Sarkar, E.V. Braden, T. Fröschl, N. Hüsing, P. Müller-Buschbaum, Spray-deposited zinc titanate films obtained via sol-gel synthesis for application in dye-sensitized solar cells, J. Mater. Chem. A 2 (2014) 15008-15014.

[71] H.S. Kim, C.H. Lee, P.K. Sudeep, T. Emrick, A.J. Crosby, Nanoparticle stripes, grids, and ribbons produced by flow coating, Adv. Mater. 22 (2010) 4600-4604.

[72] M. Mittal, R.K. Niles, E.M. Furst, Flow-directed assembly of nanostructured thin films from suspensions of anisotropic titania particles, Nanoscale 2 (2010) 2237-2243.

[73] M. Fernández-Amado, M.C. Prieto-Blanco, P. López-Mahía, S. Muniategui-Lorenzo, D. Prada-Rodríguez, Strengths and weaknesses of in-tube solid-phase microextraction: a scoping review, Anal. Chim. Acta 906 (2016) 41-57.

[74] Y. Moliner-Martinez, R. Herráez-Hernández, J. Verdú-Andrés, C. Molins-Legua, P. Campíns-Falcó, Recent advances of in-tube solid-phase microextraction, TrAC Trends Anal. Chem. 71 (2015) 205-213.

[75] J.M. Mäkelä, J. Haapanen, M. Aromaa, H. Teisala, M. Tuominen, M. Stepien, J.J. Saarinen, M. Toivakka, J. Kuusipalo, Roll-to-roll coating by liquid flame spray nanoparticle deposition, MRS Proc. 1747 (2015) mrsf14-1747-hh03-03.

[76] J.M. Mikel, M. Aromaa, H. Teisala, M. Tuominen, M. Stepien, J.J. Saarinen, M. Toivakka, J. Kuusipalo, Nanoparticle deposition from liquid flame spray onto moving roll-to-roll paperboard material, Aerosol Sci. Technol. 45 (2011) 827-837.

[77] L.J. Villarreal-Gómez, J.M. Cornejo-Bravo, R. Vera-Graziano, D. Grande, Electrospinning as a powerful technique for biomedical applications: a critically selected survey, J. Biomater. Sci. Polym. Ed. 27 (2016) 157-176.

[78] Z. Chen, Z. Chen, A. Zhang, J. Hu, X. Wang, Z. Yang, Electrospun nanofibers for cancer diagnosis and therapy, Biomater. Sci. 6 (2016) 922-932.

[79] H.-L. Chen, X.-N. Jiao, J.-T. Zhou, The research progress of Li-ion battery separators with inorganic oxide nanoparticles by electrospinning: a mini review, Funct. Mater. Lett. 9 (2016) 1630003.

[80] D.V. Talapin, J.-S. Lee, M.V. Kovalenko, E.V. Shevchenko, Prospects of colloidal nanocrystals for electronic and optoelectronic applications, Chem. Rev. 110 (2010) 389-458.

[81] H. Miguez, F. Meseguer, C. Lopez, M. Holgado, G. Andreasen, A. Mifsud, V. Fornes, Germanium FCC structure from a colloidal crystal template, Langmuir 16 (2000) 4405-4408. 
[82] O. Chen, J. Zhao, V.P. Chauhan, J. Cui, C. Wong, D.K. Harris, H. Wei, H.-S. Han, D. Fukumura, R.K. Jain, M.G. Bawendi, Compact high-quality CdSe-CdS core-shell nanocrystals with narrow emission linewidths and suppressed blinking, Nat. Mater. 12 (2013) 445-451.

[83] Y. Chen, J. Vela, H. Htoon, J.L. Casson, D.J. Werder, D.A. Bussian, V.I. Klimov, J.A. Hollingsworth, "Giant" multishell CdSe nanocrystal quantum dots with suppressed blinking, J. Am. Chem. Soc. 130 (2008) 5026-5027.

[84] W.W. Yu, E. Chang, R. Drezek, V.L. Colvin, Water-soluble quantum dots for biomedical applications, Biochem. Biophys. Res. Commun. 348 (2006) $781-786$.

[85] A. Barhoum, M. Rehan, H. Rahier, M. Bechelany, G. Van Assche, Seed-mediated hot-injection synthesis of tiny ag nanocrystals on nanoscale solid supports and reaction mechanism, ACS Appl. Mater. Interf. 8 (2016) 10551-10561.

[86] C.B. Murray, D. Norris, M.G. Bawendi, Synthesis and characterization of nearly monodisperse $\mathrm{CdE}(\mathrm{E}=\mathrm{S}$, Se, Te) semiconductor nanocrystallites, J. Am. Chem. Soc. 115 (1993) 8706-8715.

[87] J. Wu, Y. Sun, R. Zou, G. Song, Z. Chen, C. Wang, J. Hu, One-step aqueous solution synthesis of Ge nanocrystals from $\mathrm{GeO}_{2}$ powders, Cryst. Eng. Comm. 13 (2011) 3674 .

[88] Y. Zhang, A. Karatutlu, O. Ersoy, W. Little, G. Cibin, A. Dent, A. Sapelkin, Structure and effects of annealing in colloidal matrix-free Ge quantum dots, J. Synchrotron Radiat. 22 (2015) 105-112.

[89] N.H. Chou, K.D. Oyler, N.E. Motl, R.E. Schaak, Colloidal synthesis of germanium nanocrystals using room-temperature benchtop chemistry, Chem. Mater. 21 (2009) 4105-4107.

[90] A. Karatutlu, M. Song, A.P. Wheeler, O. Ersoy, W.R. Little, Y. Zhang, P. Puech, F.S. Boi, Z. Luklinska, A.V. Sapelkin, Synthesis and structure of free-standing germanium quantum dots and their application in live cell imaging, RSC Adv. 5 (2015) 20566-20573.

[91] P. Mirtchev, E.J. Henderson, N. Soheilnia, C.M. Yip, G.A. Ozin, Solution phase synthesis of carbon quantum dots as sensitizers for nanocrystalline $\mathrm{TiO}_{2}$ solar cells, J. Mater. Chem. 22 (2012) 1265-1269.

[92] M.A. Caldwell, S. Raoux, R.Y. Wang, H.-S. Philip Wong, D.J. Milliron, Synthesis and size-dependent crystallization of colloidal germanium telluridenanoparticles, J. Mater. Chem. 20 (2010) 1285-1291.

[93] P.R. Chandran, M. Naseer, N. Udupa, N. Sandhyarani, Size controlled synthesis of biocompatible gold nanoparticles and their activity in the oxidation of NADH, Nanotechnology 23 (2012) 15602.

[94] M. He, K. Kravchyk, M. Walter, M.V. Kovalenko, Monodisperse antimony nanocrystals for high-rate li-ion and na-ion battery anodes: nano versus bulk, Nano Lett. 14 (2014) 1255-1262.

[95] H. Mohammadi, A. Abedi, A. Akbarzadeh, M.J. Mokhtari, H.E. Shahmabadi, M.R. Mehrabi, S. Javadian, M. Chiani, Evaluation of synthesized platinum nanoparticles on the MCF-7 and HepG-2 cancer cell lines, Int. Nano Lett. 3 (2013) 28.

[96] T. Adschiri, K. Kanazawa, K. Arai, Rapid and continuous hydrothermal crystallization of metal oxide particles in supercritical water, J. Am. Ceram. Soc. 75 (1992) 1019-1022. 


\section{CHAPTER 1 Liquid-phase synthesis of nanoparticles and nanostructured materials}

[97] S.C. Motshekga, S.K. Pillai, S. Sinha Ray, K. Jalama, R.W.M. Krause, Recent trends in the microwave-assisted synthesis of metal oxide nanoparticles supported on carbon nanotubes and their applications, J. Nanomater. 2012 (2012).

[98] P. Lidström, J. Tierney, B. Wathey, J. Westman, Microwave assisted organic synthesis: a review, Tetrahedron 57 (2001) 9225-9283.

[99] G.E.J. Poinern, A Laboratory Course in Nanoscience and Nanotechnology, CRC Press, Boca Raton, FL, United States, (2014).

[100] D.R. Baghurst, D.M.P. Mingos, Superheating effects associated with microwave dielectric heating, J. Chem. Soc. Chem. Commun. 674 (1992) 6674-6677.

[101] R. Gedye, F. Smith, K. Westaway, H. Ali, L. Baldisera, L. Laberge, J. Rousell, The use of microwave ovens for rapid organic synthesis, Tetrahedr. Lett. 27 (1986) 279-282.

[102] S. Wu, R. Xu, M. Lu, R. Ge, J. Iocozzia, C. Han, B. Jiang, Z. Lin, Graphenecontaining nanomaterials for lithium-ion batteries, Adv. Energy Mater. 5 (2015) $1-40$.

[103] I. Bilecka, P. Elser, M. Niederberger, Kinetic and thermodynamic aspects in the microwave-assisted synthesis of $\mathrm{ZnO}$ nanoparticles in benzyl alcohol, ACS Nano 3 (2009) 467-477.

[104] N.F. Hamedani, A.R. Mahjoub, A.A. Khodadadi, Y. Mortazavi, Microwave assisted fast synthesis of various $\mathrm{ZnO}$ morphologies for selective detection of $\mathrm{CO}, \mathrm{CH} 4$ and ethanol, Sens. Actuat. B: Chem. 156 (2011) 737-742.

[105] M.A. Shenashen, S.A. El-Safty, E.A. Elshehy, Synthesis, morphological control, and properties of silver nanoparticles in potential applications, Part. Part. Syst. Charact. 31 (2014) 293-316.

[106] W. Zhang, X. Qiao, J. Chen, Synthesis of silver nanoparticles: effects of concerned parameters in water/oil microemulsion, Mater. Sci. Eng. B 142 (2007) 1-15.

[107] M. Blosi, S. Albonetti, M. Dondi, C. Martelli, G. Baldi, Microwave-assisted polyol synthesis of Cu nanoparticles, J. Nanopart. Res. 13 (2011) 127-138.

[108] S. Vijayakumar, A. Kiruthika Ponnalagi, S. Nagamuthu, G. Muralidharan, Microwave assisted synthesis of $\mathrm{Co}_{3} \mathrm{O}_{4}$ nanoparticles for high-performance supercapacitors, Electrochim. Acta 106 (2013) 500-505.

[109] T. Ramulifho, K.I. Ozoemena, R.M. Modibedi, C.J. Jafta, M.K. Mathe, Fast microwave-assisted solvothermal synthesis of metal nanoparticles (Pd, Ni, Sn) supported on sulfonated MWCNTs: Pd-based bimetallic catalysts for ethanol oxidation in alkaline medium, Electrochim. Acta 59 (2012) 310-320.

[110] S. Rodriguez-Liviano, F.J. Aparicio, T.C. Rojas, A.B. Hungría, L.E. Chinchilla, M. Ocaña, Microwave-assisted synthesis and luminescence of mesoporous RE-Doped YPO $4(\mathrm{RE}=\mathrm{Eu}, \mathrm{Ce}, \mathrm{Tb}$, and $\mathrm{Ce}+\mathrm{Tb})$ nanophosphors with lenticular shape, Cryst. Growth Des. 12 (2012) 635-645.

[111] A. Pimentel, S. Ferreira, D. Nunes, T. Calmeiro, R. Martins, E. Fortunato, Microwave synthesized $\mathrm{ZnO}$ nanorod arrays for UV sensors: a seed layer annealing temperature study, Materials 9 (2016) 299.

[112] S. Wizel, R. Prozorov, Y. Cohen, D. Aurbach, S. Margel, A. Gedanken, The preparation of metal-polymer composite materials using ultrasound radiation, J. Mater. Res. 13 (1998) 211-216.

[113] C. Yu, J.C. Yu, H. He, Progress in sonochemical fabrication of nanostructured photocatalysts, Rare Met. 35 (2016) 211-222. 
[114] H. Li, X. He, Y. Liu, H. Yu, Z. Kang, S.T. Lee, Synthesis of fluorescent carbon nanoparticles directly from active carbon via a one-step ultrasonic treatment, Mater. Res. Bull. 46 (2011) 147-151.

[115] N.A. Khan, S.H. Jhung, Synthesis of metal-organic frameworks (MOFs) with microwave or ultrasound: rapid reaction, phase-selectivity, and size reduction, Coord. Chem. Rev. 285 (2015) 11-23.

[116] V. Safarifard, A. Morsali, Applications of ultrasound to the synthesis of nanoscale metal-organic coordination polymers, Coord. Chem. Rev. 292 (2015) 1-14.

[117] A. Liberman, N. Mendez, W.C. Trogler, A.C. Kummel, Synthesis and surface functionalization of silica nanoparticles for nanomedicine, Surf. Sci. Rep. 69 (2014) $132-158$.

[118] J. Kim, J.E. Park, T. Momma, T. Osaka, Synthesis of Pd-Sn nanoparticles by ultrasonic irradiation and their electrocatalytic activity for oxygen reduction, Electrochim. Acta 54 (2009) 3412-3418.

[119] L. Sun, J. Li, C. Wang, S. Li, Y. Lai, H. Chen, C. Lin, Ultrasound aided photochemical synthesis of $\mathrm{Ag}$ loaded $\mathrm{TiO} 2$ nanotube arrays to enhance photocatalytic activity, J. Hazard. Mater. 171 (2009) 1045-1050.

[120] Y. Xing, Synthesis and electrochemical characterization of uniformly-dispersed high loading Pt nanoparticles on sonochemically-treated carbon nanotubes, J. Phys. Chem. B 108 (2004) 19255-19259.

[121] P. Kruus, Initiation of polymerization with ultrasound, Ultrasonics 25 (1987) $20-22$.

[122] S. Wizel, S. Margel, A. Gedanken, The preparation of a polystyrene-iron composite by using ultrasound radiation, Polym. Int. 49 (2000) 445-448.

[123] B.M. Teo, F. Chen, T.A. Hatton, F. Grieser, M. Ashokkumar, Novel one-pot synthesis of magnetite latex nanoparticles by ultrasound irradiation, Langmuir 25 (2009) 2593-2595.

[124] T.H. Maiman, Stimulated optical radiation in ruby, Nature 187 (1960) 493-494.

[125] L. Yang, Self-Assembly and Ordering Nanomaterials by Liquid-Phase Pulsed Laser Ablation, University of Bristol, (2007).

[126] M.A. Seo, D.S. Kim, H.S. Kim, D.S. Choi, S.C. Jeoung, Formation of photoluminescent germanium nanostructures by femtosecond laser processing on bulk germanium: role of ambient gases, Opt. Expr. 14 (2006) 4908.

[127] N.G. Semaltianos, S. Logothetidis, W. Perrie, S. Romani, R.J. Potter, S.P. Edwardson, P. French, M. Sharp, G. Dearden, K.G. Watkins, Silicon nanoparticles generated by femtosecond laser ablation in a liquid environment, J. Nanopart. Res. 12 (2009) 573-580.

[128] S.B. Ogale, P.P. Patil, S. Roorda, F.W. Saris, Nitridation of iron by pulsed excimer laser treatment under liquid ammonia: Mössbauer spectroscopic study, Appl. Phys. Lett. 50 (1987) 1802.

[129] I. Umezu, H. Minami, H. Senoo, Sugimura, a, Synthesis of photoluminescent colloidal silicon nanoparticles by pulsed laser ablation in liquids, J. Phys. Conf. Ser. 59 (2007) 392-395.

[130] Y. Jiang, P. Liu, Y. Liang, H.B. Li, G.W. Yang, Promoting the yield of nanoparticles from laser ablation in liquid, Appl. Phys. A 105 (2011) 903-907.

[131] N. Takada, T. Sasaki, K. Sasaki, Synthesis of crystalline TiN and Si particles by laser ablation in liquid nitrogen, Appl. Phys. A 93 (2008) 833-836. 


\section{CHAPTER 1 Liquid-phase synthesis of nanoparticles and nanostructured materials}

[132] V. Amendola, M. Meneghetti, What controls the composition and the structure of nanomaterials generated by laser ablation in liquid solution?, Phys. Chem. Chem. Phys. 15 (2013) 3027-3046.

[133] V.A. Svetlichnyi, A.V. Shabalina, I.N. Lapin, D.A. Goncharova, Metal oxide nanoparticle preparation by pulsed laser ablation of metallic targets in liquid. applications of laser ablation - thin film deposition, Nanomaterial Synthesis and Surface Modification, InTech, (2016). 